\title{
Redobro de clítico em português europeu
}

\section{Clitic doubling in European Portuguese}

\author{
Catarina Magro \\ Centro de Linguística da Universidade de Lisboa (Portugal) \\ cmagro@letras.ulisboa.pt
}

Recibido o 11/04/2018
Aceptado o 07/09/2018

\section{Resumo}

Este artigo investiga a construção de redobro de clítico (RC) em português europeu (PE), que se caracteriza pela dupla expressão de um argumento através de um clítico e de um pronome forte. Em PE, esta construção manifesta-se obrigatoriamente em contextos discursivos e sintáticos em que o clítico, enquanto elemento átono e necessariamente adjacente a um hospedeiro verbal, não pode receber acento prosódico nem participar em construçóes que requerem autonomia morfossintática. $\mathrm{O}$ padrão altamente restritivo da configuração de redobro nesta língua opõe o PE a outras línguas românicas, como o espanhol ou o romeno, em que o RC pode manifestar-se opcionalmente com expressões nominais plenas. Neste trabalho, procuro explicar o contraste entre o $\mathrm{RC}$ em $\mathrm{PE}$ e noutras línguas propondo que à designaçáo de RC correspondem duas construçóes distintas. Concretamente, defendo que em $\mathrm{PE}$ o clítico não é a manifestação do redobro de um argumento, como é tradicionalmente assumido nas análises para outras línguas, mas o próprio argumento redobrado. $\mathrm{Na}$ análise que apresento, clítico e pronome forte estáo associados por movimento e a configuraçáo de redobro resulta da produção das duas cópias da cadeia de movimento para satisfação de um requisito em PF. O RC em PE é, nesta perspetiva, um fenómeno de interface que envolve duas operaçóes independentemente motivadas: o movimento sintático do clítico para cliticização ao hospedeiro verbal e a realização do pronome forte em PF para atribuição de acento prosódico.

\section{Palavras-chave}

Redobro de clítico; quantificadores flutuantes; pronomes enfáticos; acento prosódico; português europeu

\section{Sumário}

1. Introdução. 2. Os dados de redobro de clítico em português europeu. 2.1. A natureza pronominal do associado. 2.2. Propriedades semânticas do associado. 2.3. O estatuto ambíguo de a. 2.4. Ordem de palavras. 2.5. Clíticos e pronomes fortes. 2.5.1. Coordenaçáo. 2.5.2. Focalizaçáo. 2.5.3. Uma nota sobre quantificação flutuante e redobro de clítico. 2.6. Redobro de clítico versus Deslocação à Esquerda Clítica e Deslocaçâo à Direita Clítica. 3. Análise. 4. Conclusôes.

\section{Abstract}

This paper investigates the clitic doubling (CD) construction in European Portuguese (EP), in which a single argument is expressed by a clitic and a strong pronoun. In EP, CD mandatorily occurs in discourse and syntactic contexts where a pronominal object must be stressed or conjoined. The highly restrictive pattern of CD in EP distinguishes this language from other Romance languages, such as Spanish and Romanian, where a clitic may optionally double full nominal expressions. This paper aims to explain the observed contrast between CD in EP and other languages arguing that the descriptive term 'clitic doubling' covers two different constructions. More specifically, it is claimed herein that in EP the clitic is not an element doubling an argument, as is traditionally assumed in the CD analyses for other languages, but the doubled argument itself. The current paper proposes that in EP the clitic is related to the strong pronoun via syntactic movement and the doubling configuration results from the spell-out of both copies of the movement chain in order to satisfy a PF requirement concerning stress assignment. $\mathrm{CD}$ in $\mathrm{EP}$ is, thus, an interface phenomenon involving two independently motivated operations: on the one hand, the syntactic movement of the clitic to attach to a verbal host, and, on the other hand, the realisation of a strong pronoun in PF to receive prosodic stress.

\section{Keywords}

Clitic doubling; floating quantifiers; emphatic pronouns; prosodic stress; European Portuguese

\section{Contents}

1. Introduction. 2. Clitic doubling data in European Portuguese. 2.1. The pronominal status of the associate. 2.2. Semantic properties of the associate. 2.3. The ambiguous status of $a$. 2.4. Word order. 2.5. Clitics and strong pronouns. 2.5.1. Conjunction. 2.5.2. Focalisation. 2.5.3. A note on floating quantification and clitic doubling. 2.6. Clitic doubling versus Clitic Left Dislocation and Clitic Right Dislocation. 3. Analysis. 4. Concluding remarks. 


\section{Introdução}

Chama-Se redobro de clítico (RC) a uma construção em que um argumento é duplamente expresso por um elemento fonologicamente dependente (um clítico) e por uma outra expressão nominal (um associado), habitualmente um DP pleno. Este fenómeno é ilustrado em (1) com um exemplo do espanhol.

(1) Le entregué las llaves al conserje. (Demonte 1995: 6)

lhe entreguei as chaves ao porteiro

'Entreguei as chaves ao porteiro'

Numa frase como a de (1), o clítico le e o associado al conserje coocorrem, realizando o argumento dativo do verbo entregar. $\mathrm{O}$ facto de as duas expressóes não ocorrerem, como se esperaria, em distribuição complementar, constitui um puzzle para a análise formal da construçáo, que, desde os trabalhos pioneiros de Strozer (1976) e Rivas (1977), tem sido alvo de grande atenção no âmbito da investigaçáo em gramática generativa ${ }^{1}$.

O RC manifesta-se em diversas línguas naturais, pertencentes a diferentes grupos $^{2}$, exibindo padrôes complexos de variação intra e interlinguística, que envolvem a função sintática, a categoria morfossintática, os traços semânticos e a função discursiva do associado. No espaço das línguas românicas, a construção delimita três grupos de línguas: (a) as línguas que produzem RC com expressóes nominais plenas e com expressôes pronominais, como o espanhol e o romeno, (b) as línguas que produzem RC apenas com expressóes pronominais, como o francês e o português, e (c) as línguas que excluem liminarmente a construção, como o italiano ${ }^{3}$. Os exemplos

1. Veja-se Anagnostopoulou (2006) e Kallulli \& Tasmowski (2008b) para sínteses do trabalho realizado sobre este tópico.

2. O RC ocorre em diversas línguas indo-europeias (búlgaro, macedónio, sérvio, esloveno, espanhol, romeno, albanês e grego) e em línguas semíticas (amárico, hebreu) (cf., entre outros, Strozer 1976; Rivas 1977; Steriade 1980; Jaeggli 1982; Borer 1984; Suñer 1988; Dobrovie-Sorin 1990; Anagnostopoulou 1994, 2006; Demonte 1995; Uriagereka 1995; Sportiche 1996; Torrego 1998; Aoun 1999; Franks \& King 2000; Philippaki-Warburton et al. 2004; Kallulli \& Tasmowski 2008a; Franks 2009; Runic 2014; Kramer 2014; Harizanov 2014; Baker \& Kramer 2016). O fenómeno está ainda documentado em trabalhos sobre o lubukusu, uma língua bantu falada no Quénia (cf. Diercks \& Sikuku 2013), e também em pirahã, uma língua da família mura falada na região do rio Maici, no Amazonas (Brasil) (cf. Everett 1987), e em kayabí, uma língua da família tupi-guarani falada no estado de Mato Grosso (Brasil) (cf. Braga 2016).

3. São muito raras as referências ao português na literatura sobre RC. Os poucos trabalhos que incluem o português na caracterização da família românica são imprecisos. Gonçalves (2015: 58) arruma o português ao lado do espanhol, opondo estas duas línguas a um outro grupo formado pelo francês e pelo italiano. Em Fischer \& Rinke (2013: 458), o português também aparece a par do espanhol por supostamente ambas as línguas admitirem redobro de expressóes nominais dativas, mas não acusativas. 
de redobro de objeto indireto apresentados de (2) a (8) ilustram o contraste entre os três grupos de línguas.

Espanhol (todas as variedades)

(2) Le di el libro a María / a ella. (Demonte 1995: 22)

lhe dei o livro a Maria / a ela

'Dei o livro à Maria / Dei-lhe o livro a ela'

\section{Romeno}

(3) I-am dat cărţi Mariei / ei. (Dobrovie-Sorin 1990: 355)

lhe-temos dado livros Maria $_{\mathrm{DAT}} /$ ela $_{\mathrm{DAT}}$

'Nós temos dado livros à Maria / Nós temos-lhe dado livros a ela'

Francês

(4) * Jean lui parle a Marie. (Kayne 2000: 165)

João lhe fala a Maria

'O João fala à Maria'

(5) Jean lui parle a elle.

João lhe fala a ela

'O João fala-lhe a ela'

Português

(6) * Dei-lhe o livro à Maria.

(7) Dei-lhe o livro a ela.

Italiano

(8) * Gli ho dato un libro a Carlo / a lui ieri. (Cordin \& Calabrese 1988: 571)

lhe tenho dado um livro a Carlo / a ele ontem

'Dei um livro ao Carlo ontem / Dei-lhe um livro a ele ontem'

Os dados acima mostram claramente que a natureza nominal/pronominal do associado é um dos eixos de variação da construção. A assimetria entre associados nominais e pronominais foi inicialmente identificada por Jaeggli (1982), a propósito de dados do espanhol, e levou recentemente Fischer \& Rinke (2013) a proporem uma hierarquização do parâmetro de RC, na linha de Roberts \& Holmberg (2010) e Roberts (2012), em que o redobro de pronomes fortes ocupa uma posição alta na hierarquia: 
(9) Hierarquia do parâmetro de RC (Fischer \& Rinke 2013: 468)

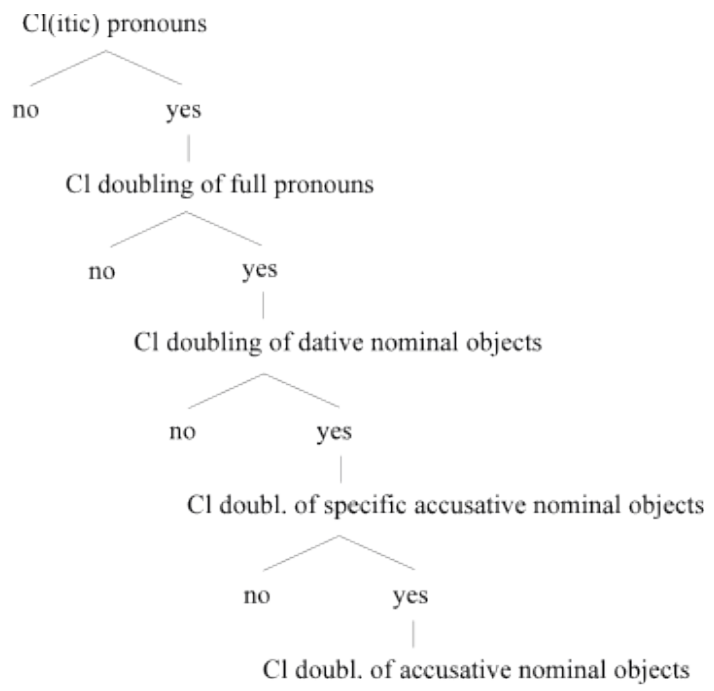

A hierarquia de Fischer \& Rinke (2013) capta devidamente a relação implicacional existente entre o redobro pronominal e nominal nas línguas românicas: como mostrei acima, todas as línguas que dispóem de redobro de expressóes nominais plenas dispóem necessariamente de redobro de pronomes (é o caso do espanhol e do romeno), não sendo verdadeira a implicaçáo inversa (é o caso do francês e do português). Parece, no entanto, que o contraste entre os dois tipos de RC vai para além da assimetria da implicação. Com efeito, nas línguas de redobro consideradas, verifica-se que o RC com expressóes nominais é sempre um fenómeno opcional, ao contrário do que se observa com o RC com pronomes, que tem um caráter obrigatório em todos os casos. Os dados de redobro de objeto direto em (10) a (17) ilustram este outro contraste.

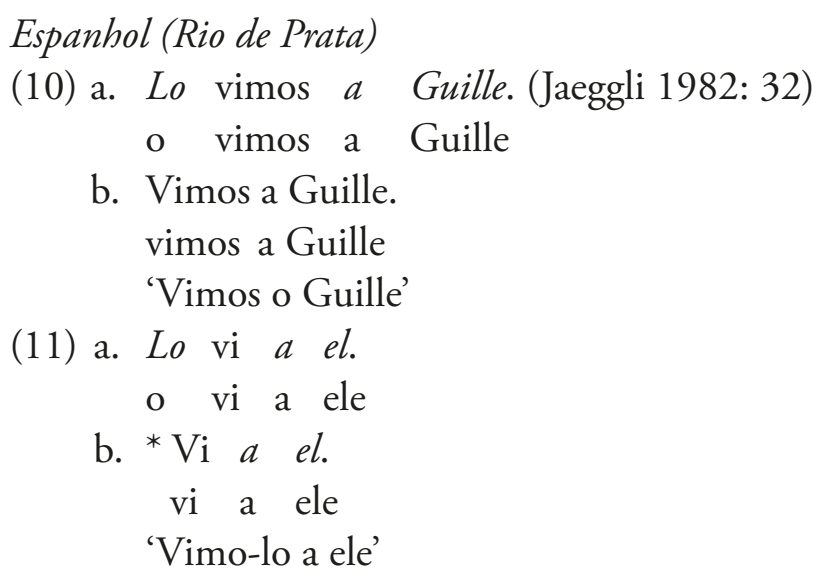


Romeno

(12) a. Ion $l$-a examinat pe vecin. (Dobrovie-Sorin 1990: 355)

João o-tem examinado $\mathrm{PE}$ vizinho

b. Ion a examinat vecinul.

João tem examinado vizinho $_{\mathrm{AC}}$

'O João tem examinado o vizinho'

(13) a. Ion $l$-a examinat pe el.

João o-tem examinado $\mathrm{PE}$ ele

b. *Ion a examinat pe el.

João tem examinado PE ele

'O Joáo tem-no examinado a ele'

Francês

(14) * Jean la connait Marie. (Kayne 2000: 165)

Joáo a conhece Maria

'O João conhece a Maria'

(15) a. Jean la connait elle.

Joáo a conhece ela

b. * Jean connait elle.

João conhece ela

'O João conhece-a a ela'

Português

(16) * Vimo-lo ao Joâo.

(17) a. Vimo-lo a ele.

b. *Vimos (a) ele.

O quadro de variação que sai destes dados está sistematizado na Tabela $1^{4}$.

\begin{tabular}{lcccc} 
& \multicolumn{2}{c}{ associado nominal } & \multicolumn{2}{c}{ associado pronominal } \\
\cline { 2 - 5 } & O. Indireto & O. Direto & O. Indireto & O. Direto \\
\hline Esp. Peninsular & \pm & - & + & + \\
Esp. Rio da Prata & \pm & \pm & + & + \\
Romeno & \pm & \pm & + & + \\
Francês & - & - & + & + \\
Português & - & - & + & + \\
Italiano & - & - & - & - \\
\hline
\end{tabular}

Tabela 1. RC nas línguas românicas; legenda: \pm opcional; + obrigatório; - impossível

4. O fenómeno de RC é sensível a outras propriedades do associado, nomeadamente aos seus traços semânticos, que não estou para já a incluir nesta descrição. Assim, a Tabela 1 apresenta os dados relativos aos objetos que são tipicamente redobrados, i. e., objetos com os traços [+animado] [+definido] [+ específico]. 
Os valores apresentados na Tabela 1 mostram que a categoria morfossintática do associado está na base de um contraste tipológico, que opóe dois grupos de línguas românicas ${ }^{5}$, mas também na base de um contraste gramatical relativo à opcionalidade vs obrigatoriedade do redobro.

A partir desta constatação, gostaria de sugerir que sob a designação genérica de 'redobro de clítico' cabem, na verdade, duas construçóes distintas: (i) uma construção em que um argumento nominal é (opcionalmente) redobrado por um clítico e (ii) uma construção em que um clítico argumental é (obrigatoriamente) redobrado por um pronome forte. A diferença central está, pois, na relação que se estabelece entre o clítico e o associado: em (i) o clítico é o 'duplo'; em (ii) o associado é o 'duplo'.

Neste trabalho, vou tentativamente explorar esta hipótese a partir da discussão de dados do português e defender que a construção descrita em (ii) - a única existente nesta língua - se aplica sempre que um objeto pronominal requer acento prosódico e/ou autonomia morfossintática. Desejavelmente, os resultados obtidos para o português serão facilmente estendidos ao francês.

$\mathrm{O}$ artigo está organizado da seguinte forma: A secção 2. é dedicada à caracterização da construção de $\mathrm{RC}$ em $\mathrm{PE}$. Começo por discutir o estatuto categorial do associado na secção 2.1. mostrando que este é em todos os casos uma forma oblíqua de um pronome pessoal, compatível com quantificadores que admitem flutuação; na secção 2.2., procuro provar que o redobro impóe condiçóes sobre as propriedades semânticas do associado relativas aos traços de animacidade, definitude e especificidade; na secção 2.3., mostro que a Generalização de Kayne é operativa em PE e que o elemento $a$ que introduz o associado é funcionalmente ambíguo entre uma marca de Caso e de animacidade; a secção 2.4. trata da distribuição sintática do associado e apresenta evidência de que este ocupa uma posição-A interna a VP; o contraste entre as propriedades de clíticos e pronomes fortes é discutido na secção 2.5., o que permite delimitar os contextos sintáticos e discursivos em que as duas classes de pronomes necessariamente coocorrem; finalmente, a secção 2.6. é destinada a diferenciar a construção de RC de duas outras construçôes superficialmente idênticas: a Deslocação à Esquerda Clítica e a Deslocação à Direita Clítica. Com base na descrição apresentada na secção 2., avanço uma proposta de análise do RC em PE na secção 3., mostrando antes que as principais análises do fenómeno existentes na literatura não captam o padráo de redobro que se manifesta nesta língua. De acordo com a minha proposta, clítico e pronome forte correspondem a uma única categoria, estando as duas formas associadas por movimento sintático; a configuração de redobro resulta da produção das duas cópias da cadeia de movimento para satisfação de um requisito em PF relativo a acento prosódico. A secção 4. encerra o artigo com as principais conclusóes.

5. A restrição do $\mathrm{RC}$ a categorias pronominais regista-se igualmente em línguas exteriores ao espaço românico, o que confirma o estatuto especial do redobro pronominal. É o caso de certos dialetos do sérvio e do esloveno (Runic 2014) e também do lubukusu (Diercks \& Sikuku 2013). 


\section{Os dados de redobro de clítico em português europeu}

Conforme vimos acima, a chamada construção de $\mathrm{RC}$ em português europeu (PE) reveste-se de propriedades particulares: o redobro é obrigatório com pronomes fortes e agramatical com DPs plenos, afetando indistintamente objetos dativos e acusativos (Matos 2003: 832-833) . O paradigma da construção é o apresentado em (18)-(21).

(18) a. O Pedro telefonou-lhe a ela.

b. ${ }^{*} \mathrm{O}$ Pedro telefonou a ela.

(19) a. * O Pedro telefonou-lhe à Ana.

b. O Pedro telefonou à Ana.

(20) a. O Pedro encontrou- $a$ a ela.

b. * O Pedro encontrou (a) ela.

(21) a. * O Pedro encontrou- $a$ à Ana.

b. O Pedro encontrou a Ana.

Morais (2006), num trabalho sobre construçóes dativas, avança uma proposta de tratamento do RC em PE, a única, tanto quanto sei, existente para esta língua. Nesse trabalho, a autora defende que, à semelhança do inglês, o PE é uma língua de alternância dativa, dispondo (a par de uma estrutura ditransitiva preposicionada) de uma estrutura de duplo objeto ${ }^{7}$. Segundo Morais (2006), e na linha de Pylkkänen (2002) e de Cuervo (2003), a estrutura de duplo objeto do PE envolve um sintagma Aplicativo (ApplP) baixo, no interior do qual se estabelece uma relação dinâmica de transferência de posse entre um DP dativo (destinatário, origem, beneficiário) e um DP acusativo, que ocupam, respetivamente, as posições de especificador e complemento de ApplP.

No âmbito desta proposta, o RC é analisado como um fenómeno de concordância. Concretamente, na configuração de redobro, o clítico é a expressão morfológica do núcleo Appl, realizando os traços de pessoa e número do DP dativo especificador. $\mathrm{Na}$ variante sem redobro, pelo contrário, o clítico não é um morfema de concordância, mas um DP dativo argumental projetado na posição de especificador. $\mathrm{O}$ núcleo Appl, neste caso, não é lexicalmente realizado. As estruturas abaixo representam as duas variantes.

6. A construção de RC é objeto de variação dialetal e diacrónica em português. Com efeito, o redobro de DPs plenos, como em (19a) e (21a), e a utilizaçáo de pronomes fortes em substituiçáo dos correspondentes pronomes clíticos, como em (18b) e (20b), são construçóes atestadas em diversas fontes históricas e dialetais. Embora o presente artigo não incida sobre estes dados, a que darei atenção noutro trabalho, reúno no Apêndice final uma seleção de exemplos relevantes para a caracterização do quadro de variação que a construção apresenta.

7. Já Uriagereka (1988: 358-363) tinha feito uma proposta nesta linha para o galego analisando como instâncias de duplo objeto as construçôes com redobro de clítico dativo. 


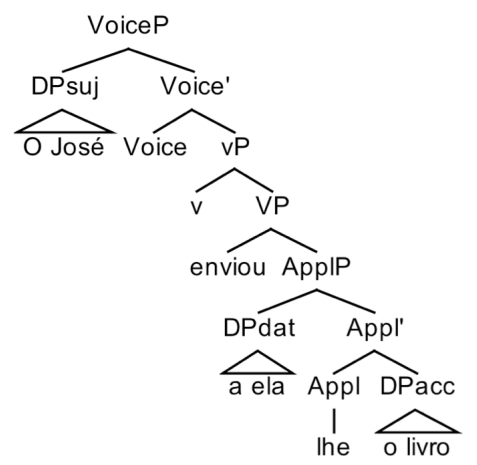

(23) Estrutura sem RC

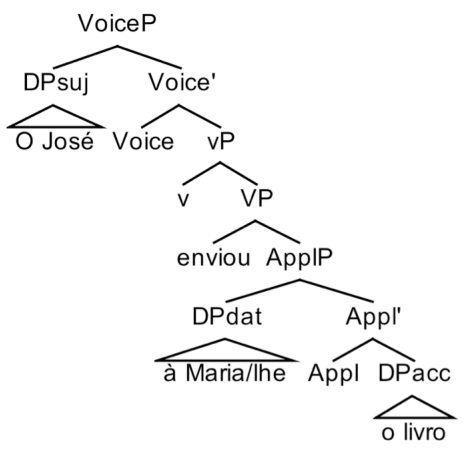

(adaptado de Morais 2006: 256)

A discussão da hipótese central de Morais (2006) - a de que o PE dispóe de uma construção de duplo objeto aplicativa - está totalmente fora do âmbito deste artigo e a este respeito remeto o leitor interessado para os trabalhos de Brito (2009) e Gonçalves (2015). Interessa-me, contudo, analisar a proposta relativa ao $\mathrm{RC}$, que me parece deixar por explicar várias das propriedades desta construção em PE. Desde logo, o RC em PE é um fenómeno transversal a diferentes construçóes dativas, algumas delas dificilmente analisáveis como construçôes aplicativas (cf. Miguel, Gonçalves \& Duarte 2011). No mesmo sentido, os casos de redobro de objetos acusativos, como os de (20), são problemáticos para uma análise do redobro assente na existência de nós aplicativos. Mas é sobretudo a incapacidade de excluir dados como os de (18b) ou (19a) que considero ser a maior fragilidade da proposta de Morais (2006). Quero eu dizer: na estrutura (22), o que é que impede um DP pleno de ocupar a posição de especificador de ApplP? E inversamente: na estrutura (23), o que é que impede um DP pronominal de ocupar a posição de especificador de ApplP?

Note-se que náo há nada de errado em analisar o RC como um fenómeno de concordância de objeto. Essa tem sido, aliás, uma das linhas de análise do RC em várias línguas (cf., entre outros, Suñer 1988, Sportiche 1996 e Franco 2000, para as línguas românicas, Franks \& King 2000, para as línguas eslavas, e Anagnostopoulou 2016, para as línguas bantu). O problema é que, à partida, a partilha de traços- $\varphi$ entre um DP objeto e um clítico numa configuração de especificador-núcleo não requer um especificador pronominal, e, contudo, uma análise do RC em PE terá sempre de excluir a possibilidade de redobro de DPs plenos. Na secção 3, apresento uma hipótese de análise que procura satisfazer este requisito. Antes de cumprir esse objetivo, dedicarei as subsecçôes seguintes a caracterizar a construção mais detalhadamente. 


\subsection{A natureza pronominal do associado}

Numa configuração de redobro, podem desempenhar a função de associado as formas oblíquas dos pronomes pessoais: mim, ti, elelela, si, nós, vós/vocês, eles/elas. Estes pronomes podem ocorrer quer isoladamente, como vimos até agora, quer em combinação com certas expressôes quantificacionais. Os exemplos abaixo ilustram a possibilidade de combinação de pronomes plurais com o quantificador universal todos (cf. 24) e com constituintes compostos por artigo definido e numeral cardinal (cf. 25).

(24) a. A agência ofereceu-lhes a viagem a eles todos / a todos eles.

b. O professor reprovou-nos a nós todos / a todos nós.

(25) a. A agência ofereceu-vos a viagem a vocês os dois.

b. O professor reprovou-os a eles os três.

Como se sabe, os pronomes pessoais oblíquos podem participar igualmente em estruturas de quantificação partitiva, embora, nesse caso, não possam desempenhar o papel de associado em contextos de redobro:

(26) a. * A agência ofereceu-lhes a viagem a vários deles.

b. ${ }^{*} \mathrm{O}$ professor reprovou-vos a três de vocês/vós.

Este contraste leva-me a formular a seguinte generalização:

(27) Em construçôes de RC, os pronomes só podem combinar-se com quantificadores que admitem flutuação.

Veja-se o paralelismo entre o contraste observado acima e o apresentado abaixo: os quantificadores de (24)-(25), que participam em construçóes de redobro, são os quantificadores flutuantes de (28)-(29); paralelamente, os quantificadores de (26), excluídos de construçóes de redobro, são aqueles que em (30) ocorrem obrigatoriamente junto do pronome, não podendo "flutuar".

(28) a. Eles todos foram viajar. / Eles foram todos viajar.

b. Nós todos reprovámos no exame. / Nós reprovámos todos no exame.

(29) a. Vocês os dois foram viajar. / Vocês foram os dois viajar.

b. Eles os três reprovaram no exame. / Eles reprovaram os três no exame.

(30) a. Vários deles foram viajar. / * Eles foram vários viajar.

b. Três deles reprovaram no exame. ${ }^{*}$ Eles reprovaram três no exame. 
A relação entre $\mathrm{RC}$ e quantificação flutuante sai reforçada quando se observa o comportamento do quantificador universal ambos. O argumento é o seguinte: quando quantificados, os pronomes do associado podem ser foneticamente nulos, como mostram os exemplos de (31)-(32).

(31) a. A agência ofereceu-lhes a viagem $a$ _ todos / a todos

b. O professor reprovou-nos a _ todos / a todos

(32) a. A agência ofereceu-vos a viagem $a$ _os dois.

b. O professor reprovou-os a _os três.

Os pronomes dos associados em (31)-(32) são, pois, a contrapartida nula dos pronomes realizados em (24)-(25) ${ }^{8}$. Curiosamente, o RC com ambos - um quantificador universal semelhante a todos - não exibe o mesmo comportamento:

(33) a. * A agência ofereceu-lhes uma viagem a eles ambos / a ambos eles.

b. A agência ofereceu-lhes uma viagem $a$ ambos.

Este contraste é, no entanto, o mesmo que se verifica ocorrer em contextos de quantificação sobre o sujeito: quando ambos se combina com um pronome, o quantificador é necessariamente pós-verbal (cf. 34a), não podendo quantificador e pronome ocorrer em posições contíguas (cf. 34b). Irei defender que a mesma restrição opera em contextos de $\mathrm{RC}$ e assumir que também em (33b) o associado contém um pronome nulo.

(34) a. Eles foram ambos viajar.

b. * Ambos eles foram viajar.

Tira-se daqui que o RC em PE é em todos os casos redobro pronominal', poden-

8. Note-se, no entanto, que em (31)-(32), a categoria nula é inequivocamente pronominal, sendo agramaticais versôes das mesmas frases com nomes produzidos nas posições assinaladas:

(i) * A agência ofereceu-lhes a viagem a todos os funcionários.

(ii) * O professor reprovou-os aos três alunos.

9. Segundo os juízos de um revisor anónimo, expressões nominais com interpretação grupal também podem desempenhar a função de associado em configuraçôes de redobro. São aceites pelo revisor exemplos como os seguintes:

(i) O professor reprovou-nos à turma inteira.

(ii) Ela viu-os ao grupo todo.

Não há, no entanto, atestações de dados deste tipo no Corpus de Referência do Português Contemporâneo (CRPC) do Centro de Linguística da Universidade de Lisboa. A pesquisa foi feita através da plataforma CQPWeb, no período de julho de 2018, sobre o subcorpus do PE do CRPC (versão 2.3 2012), que tem uma extensão de $289,840,619$ palavras, distribuídas por 332,332 textos orais e escritos de diferentes géneros. Foram pesquisadas ocorrências de redobro com os 57 nomes coletivos que 
do os pronomes que participam da construção ser ou não quantificados. No caso de o serem, podem ser foneticamente realizados ou nulos. As condiçóes que regulam a sua realização serão discutidas na secção 3 .

\subsection{Propriedades semânticas do associado}

O RC em PE é transversal a diferentes construçóes dativas e acusativas, não sendo sensível à natureza argumental/não argumental do objeto redobrado nem ao papel- $\theta$ que lhe está associado. Assim, por exemplo, o RC ocorre em frases com dativos argumentais com interpretação de destinatário (cf. 35a), origem (cf. 35b) ou experienciador (cf. 35c), mas também em frases com dativos náo argumentais, como o dativo de posse de (35d) e o dativo benefactivo de $(35 \mathrm{e})^{10}$. Com acusativo, podem ser redobrados argumentos com o papel- $\theta$ tema (cf. 36a), paciente (cf. 36b), experienciador (cf. 36c) ou estímulo (cf. 36d).

(35) a. Entregámos-lhes a chave a eles.

b. Os vizinhos compraram-nos o andar de baixo a nós.

c. A ópera agradava-lhe mais a ela.

d. O meu irmão partiu-me a cabeça a mim.

e. Os amigos preparam-lhe uma festa surpresa a ela.

(36) a. O pai só te levou a ti a Paris.

b. O patrão culpou-vos a vocês pelo acidente.

c. A notícia preocupou-o muito a ele.

d. Não gosta de ninguém, mas odeia- $a$ especialmente $a$ ela.

A possibilidade de redobro é, no entanto, excluída em estruturas com dativos éticos, facto já assinalado por Miguel, Gonçalves \& Duarte (2011) e ilustrado pelo par de frases em (37).

(37) a. Para-me já com essa choradeira!

denotam conjuntos de pessoas listados em Raposo (2013b: 979-980).

Note-se, porém que certos dialetos setentrionais e insulares do PE admitem RC com DPs plenos, nomeadamente com nomes coletivos, como mostra o exemplo (xv) do Apêndice final deste artigo, que aqui repito:

(iii) Bota-lhe agora o milho ao gado. [CORDIAL-SIN, STA01,4]

É possível, pois, que, entre os dialetos que produzem RC com DPs plenos, haja variedades que imponham restrições semânticas ao associado no que respeita à sua interpretaçấo grupal. Agradeço ao revisor ter-me chamado a atenção para este aspeto, que irei considerar noutro contexto (cf. nota 6).

10. Adoto neste trabalho a tipologia de papéis temáticos apresentada em Raposo (2013a: 373-380). A categorização dos dativos não argumentais é a de Miguel, Gonçalves \& Duarte (2011). 


\section{b. * Para-me já com essa choradeira a mim!}

Importa, contudo, notar que, para além de não admitirem redobro, os dativos éticos se opóem em vários aspetos aos dativos apresentados em (35). Para o que está aqui em jogo, são relevantes as seguintes diferenças sintáticas: (i) os dativos éticos são necessariamente realizados sob a forma de clíticos, não podendo alternar com PPs em posiçóes-A (cf. 38); (ii) os dativos éticos não admitem movimento-A' (cf. 39); (iii) os dativos éticos podem coocorrer com outros constituintes dativos (cf. 40). Estes factos são conhecidos desde Perlmutter (1971).

(38) * Para já com essa choradeira ao pai!

(39) * A quem é que paras com essa choradeira?

(40) Lá me foram dizer essa parvoíce à Joana!

Com base nestes e noutros argumentos, vários autores defendem que os dativos éticos não estão associados a uma posição estrutural no domínio funcional de VP, sendo gerados diretamente numa projeção funcional da periferia esquerda que codifica afetação/avaliação dos participantes do discurso relativamente ao evento descrito (cf., para diferentes hipóteses de implementação desta proposta, Adger \& Harbour 2007; Boneh \& Nash 2009; Miguel, Gonçalves \& Duarte 2011; Michelioudakis \& Kapogianni 2013).

Pelo contrário, e de acordo com Miguel, Gonçalves \& Duarte (2011), os dativos de posse e os dativos benefactivos, embora também não integrem a grelha argumental do verbo com que ocorrem, são gerados internamente ao DP-tema selecionado pelo verbo (nos exemplos de (35d) e de (35e), a cabeça e uma festa surpresa, respetivamente), o que os coloca, consequentemente, numa posição interna ao domínio funcional de VP.

Defenderei adiante que a associação do clítico a uma posição interna a VP é crucial para que a operaçáo de redobro se verifique. Será, portanto, esta diferença entre os dativos éticos e todos os outros o que justificará o contraste entre a gramaticalidade dos exemplos em (35) e a agramaticalidade do exemplo (37b).

Outro dos aspetos que habitualmente condicionam o $\mathrm{RC}$ relaciona-se com os traços léxico-semânticos do objeto. Com efeito, na maioria das línguas de redobro, verifica-se que só são redobráveis objetos com os traços [+animado] [+definido] e com interpretação específica (cf. Borer 1984; Suñer 1988; Dobrovie-Sorin 1990; Enç 1991). No contexto das línguas românicas, esta generalização é válida para o espanhol peninsular e para o romeno. Vou estendê-la agora ao português, mostrando que os pronomes fortes - as únicas categorias redobráveis nesta língua - gozam destas propriedades semânticas.

Sabe-se desde Uriagereka (1995) e Sportiche (1996) que os clíticos complemento das línguas românicas são inerentemente específicos (a este respeito, ver também Ro- 
berts 2010). Um dos exemplos clássicos que comprova esta propriedade dos pronomes clíticos é o que se apresenta em (41)-(42): o DP indefinido um italiano de olhos verdes só pode ser retomado por um clítico no caso em que recebe uma interpretação específica ${ }^{11}$ :

(41) A: A Maria quer casar com um italiano de olhos verdes. (leitura específica) B: Onde é que ela $o$ conheceu?

(42) A: A Maria quer casar com um italiano de olhos verdes. (leitura não específica) B: Não é fácil encontrar um. / * Não é fácil encontrá-lo.

O mesmo efeito se obtém com pronomes fortes. O exemplo abaixo é um exemplo do inglês de Karttunen (1976): enquanto em (43) o DP indefinido a girl pode ser específico ou não específico, em (44), caso em que é retomado por um pronome forte, o DP é necessariamente específico. Os resultados seriam equivalentes na versão portuguesa do exemplo.

(43) Harvey courts a girl at every convention. (Karttunen 1976: 377)

(44) Harvey courts a girl at every convention. She is pretty.

A especificidade dos pronomes parece, pois, confirmada. Quanto à propriedade de definitude, vou assumir, com Raposo (2013c: 909), que os pronomes têm sempre uma interpretação definida. Ou seja, a referência de um pronome é sempre identificada, quer seja fixada deiticamente por ancoragem às coordenadas do ato de enunciação, quer seja construída anaforicamente por retoma de uma expressão nominal, definida ou indefinida, anteriormente introduzida no discurso. A possibilidade linguística de construir cadeias anafóricas com o formato $\mathrm{X}_{[- \text {definido }]}-\mathrm{Y}_{[+ \text {definido] }}$ é discutida para o português em Oliveira (1987). Esta capacidade de definitização, própria das cadeias anafóricas, é testemunhada abaixo com exemplos de RC:

(45) [ + específico, + definido]

Costumava ver o Pedro e a Luísa pela faculdade, mas já não $a$ encontro $a$ ela há muito tempo.

(46) [ + específico, - definido]

Morava por baixo de um baterista e por cima de uma filatelista, mas surpreendentemente ouvia- $a$ mais a ela que a ele.

(= ouvia mais a filatelista que morava por baixo)

(47) [ - específico, + definido]

O presidente apoiaria o atleta que vencesse a maratona, embora não $o$ fosse condecorar a ele, mas sim ao treinador.

(= o presidente não ia condecorar $o$ atleta que tivesse vencido)

11. Veja-se a discussão de dados semelhantes em Peres (2013: 801-806). 
(48) [ - específico, - definido]

Aconselharam-me esta tradutora, mas, se eu encontrar um especialista em teatro Russo, contrato-o antes a ele.

(= contrato $o$ especialista em teatro Russo)

Estes dados mostram que os mecanismos de construção da referência de um pronome anafórico podem envolver o reprocessamento da especificidade/definitude do antecedente. Nada de semelhante se passa com a propriedade de animacidade (como, aliás, se esperaria, já que esta nada tem a ver com referência): um pronome forte anafórico requer sempre um antecedente com o traço [+ animado] (ou até mesmo [+ humano]). A animicidade do objeto é, pois, condição necessária para que o RC se verifique em português ${ }^{12,13}$ :

(49) a. * O Luís gostou tanto daquele candeeiro que acabou por $o$ fotografar $a$ ele para o concurso.

b.? O Luís gosta tanto do cão que acabou por $o$ fotografar a ele para o concurso.

c. O Luís está táo apaixonado pelo filho que acabou por $o$ fotografar a ele para o concurso.

Em suma, à semelhança do que acontece na maioria das línguas de redobro, o RC em PE impóe condiçóes sobre as propriedades semânticas do associado, restringindo a possibilidade de redobro a objetos com os traços [+ animado/humano], [+ definido] [+ específico].

\subsection{O estatuto ambíguo de $a$}

Atravessa a literatura sobre $\mathrm{RC}$ a discussão acerca de uma generalização originalmente atribuída a R. Kayne por Jaeggli (1982). Tornou-se conhecida como Generalização de Kayne e postula o seguinte: "An object NP may be doubled by a clitic only if the NP is preceded by a preposition" (Jaeggli 1982: 20). Frases como as de (10a)-(11a), do espanhol, ou (12a)-(13a), do romeno, são exemplo de dados que observam esta generalização: os objetos acusativos redobrados são precedidos de $a$ ou de $p e$, respetivamente.

12. Os pronomes fortes em português europeu denotam preferencialmente entidades com o traço [+animado] ou, para os falantes mais restritivos, com o traço [+humano]. Estas restriçôes de interpretação dos pronomes fortes são, contudo, um tópico de variação em português. Veja-se sobre o assunto Raposo (1998: 21, 2013c). Sobre o contraste entre pronomes fortes e clíticos relativamente a este aspeto, veja-se Kayne (1975: 86) e Cardinaletti \& Starke (1999).

13. Gonçalves (2015: 59, nota 9) sugere que o redobro do PE é independente da animacidade do associado. Contudo, não apresenta dados que sustentem esta afirmação. 
Também em português se verifica a condição descrita por Jaeggli-Kayne: numa configuração de redobro, o objeto redobrado é obrigatoriamente introduzido por $a$, mesmo que corresponda a um acusativo:

(50) a. O Pedro encontrou- $a$ a ela.

b. * O Pedro encontrou- $a$ ela.

Inicialmente, a preposição de Jaeggli-Kayne foi considerada um atribuidor de Caso ao associado, responsável por satisfazer o Filtro do Caso e salvar a derivação (já que o clítico absorvia o Caso estrutural atribuído pelo verbo), mas o entendimento sobre o estatuto desta preposiçáo foi-se alterando ao longo do avanço da investigaçáo sobre $\mathrm{RC}^{14}$. Suñer (1988) é a primeira de vários autores que se afastam da abordagem baseada na Teoria do Caso e defendem que este elemento de tipo preposicional é um marcador das propriedades semânticas do associado e/ou do predicador verbal com que ocorre (cf. também Dobrovie-Sorin 1990; Schmitt 1996; Torrego 1998; Cardinaletti \& Starke 1999).

Concretamente, Suñer (1988: 399-400) propóe que o elemento a que introduz o associado no RC em espanhol é um marcador de animacidade, o que também parece ajustar-se convenientemente aos dados do português ${ }^{15}$. Nesta língua, a relação entre a ocorrência de $a$ e animacidade torna-se particularmente evidente quando se compara a quantificação flutuante de objeto com o RC com pronomes nulos quantificados (cf. secção 2.1.). As duas construçôes estão exemplificadas em (51). Em ambas, o objeto é [+ humano].

(51) a. Os miúdos não vão estar em casa. Vi-os todos na manifestação.

b. Os miúdos não vão estar em casa. Vi-os a todos na manifestação.

14. Os argumentos para o abandono/reajuste da perspetiva inicial são vários e diferem de língua para língua. Veja-se Anagnostopoulou (2006) e Kallulli \& Tasmowski (2008b) para uma síntese da questão.

15. Curiosamente, Gonçalves (1990) chega à mesma conclusão por um caminho que não me parece, contudo, validá-la. Com base no contraste abaixo, a autora conclui que a preposiçáo $a$ "está associada à presença do traço [+ ANIM]/ [+ HUM] nos constituintes que rege” (Gonçalves 1990: 102):

(i) a. A Dina viu o tio.

b. A Dina viu-o a ele.

(ii) a. A Dina viu um disco voador.

b. * A Dina viu-o a ele.

Considero, no entanto, que o que torna (iib) agramatical é o uso do pronome ele $e_{[- \text {humano] }}$ e não propriamente as restriçóes de seleção da preposiçáo $a$. A ocorrência de ele ${ }_{[- \text {humano] }}$ numa frase sem RC (e, portanto, sem a preposição a) seria igualmente agramatical:

(iii) A Dina viu um disco voador. * Ele tinha luzinhas a piscar. 
A construçáo de RC deixa, no entanto, de ser possível com objetos com o traço [- humano]:

(52) a. Já não há biscoitos de aveia, que eu comi-os todos.

b. * Já não há biscoitos de aveia, que eu comi-os a todos.

Inversamente, a construção de quantificação flutuante é agramatical com argumentos cujo traço [+ humano] é exigido pelo verbo:

(53) a. * A notícia preocupou-os todos.

b. A notícia preocupou-os a todos.

E o mesmo acontece nos casos em que o argumento é realizado sob a forma de um clítico de $1 .^{\mathrm{a}}$ ou $2 .^{\mathrm{a}}$ pessoa, necessariamente dotado do traço [+ humano]:

(54) a. ${ }^{*} \mathrm{O}$ novo diretor conheceu-vos todos na tomada de posse.

b. O novo diretor conheceu-vos a todos na tomada de posse.

Então, o quadro parece ser o seguinte:

- quando as restrições de seleção do predicador verbal não são sensíveis à dimensão humana/não humana do argumento, ambas as construçôes são possíveis. É o que se verifica em (51): a natureza humana do argumento interno nas duas frases em (51) não corresponde a uma imposição do predicador (ver seleciona argumentos internos [ \pm humano]) e a ocorrência de $a$ é opcional.

- quando o predicador se combina com um argumento necessariamente [- humano], como acontece em (52), a ocorrência de a é agramatical.

- quando o argumento é necessariamente [+ humano], seja essa propriedade consequência da configuraçáo de traços- $\varphi$ do argumento (cf. o pronome de $2 .^{\mathrm{a}} \mathrm{p}$. de (54)) ou consequência das restriçóes de seleção do predicador (cf. o experienciador de (53)), a ocorrência de $a$ é obrigatória.

É tentador tomar estes resultados como evidência empírica para afirmar que o elemento a que introduz o associado em configuraçôes de RC é um marcador de animacidade. Note-se, porém, que nos contextos em que as duas construçóes são possíveis, como em (51), só a construção de RC legitima a realização do pronome forte, o que sugere que $a$, independentemente da correlaçáo com animacidade que superficialmente se observa, funciona de facto como um atribuidor/marcador de Caso: 
(55) a. * Os miúdos não vão estar em casa. Vi-os eles todos / todos eles na manifestação.

b. Os miúdos não vão estar em casa. Vi-os a eles todos / a todos eles na manifestação.

Até aqui a argumentação correu com base em objetos acusativos. As conclusóes são, no entanto, extensíveis aos dativos, embora mais dificilmente comprováveis. Por um lado, porque os argumentos dativos são tipicamente [+ animado] (cf. Duarte 2003: 289 $)^{16}$, por outro, porque a ocorrência de $a$ como introdutor de dativos é sempre obrigatória para atribuição/marcação de Caso (independentemente da marcação de animacidade que possa adicionalmente envolver).

Com base nas conclusóes do alargado debate sobre a natureza categorial dos dativos em PE, vou simplesmente assumir que, também nas estruturas de RC, o associado dativo não é um verdadeiro $\mathrm{PP}$, mas um DP marcado casualmente por $a^{17}$. Categorialmente, associados acusativos e dativos são, pois, equivalentes.

Sáo muitos os argumentos apresentados na literatura a favor do chamado $a$-DP (ver nota 17). Aqui, vou apresentar dois que se relacionam diretamente com RC (cf. Morais 2006: 258 e Gonçalves \& Raposo 2013: 1178-1179 para a discussão de dados semelhantes):

- Os benefactivos introduzidos por para não admitem redobro ${ }^{18}$, ao contrário dos introduzidos por $a$, como já tínhamos visto acima (cf. 57). Note-se ainda que para, mas náo $a$, legitima um pronome forte náo redobrado (cf. 58). Assumindo que para é uma verdadeira preposição, estes dados mostram que o redobro é impossível com PPs e possível com $a$-DPs:

(56) a. O António fez uma torre de Lego ao filho.

b. O António fez uma torre de Lego para o filho.

(57) a. O António fez-lhe uma torre de Lego a ele.

b. * O António fez-lhe uma torre de Lego para ele.

(58) a. * O António fez uma torre de Lego a ele.

16. Isto pode explicar porque é que há línguas com RC de dativos, mas não de acusativos. Veja-se a hierarquia do parâmetro de RC em (9) e a discussão sobre a caracterização semântica inerente de dativos versus acusativos em Fischer \& Rinke (2013: 466-467).

17. O debate sobre a categoria dos objetos indiretos foi iniciado para o francês por Vergnaud (1974) e originalmente importado para o português por Duarte (1987). Para o português, Gonçalves (1990), Morais (2006), Brito (2009), Miguel, Gonçalves \& Duarte (2011) e Gonçalves (2015) são alguns dos trabalhos que retomam e estendem as conclusóes iniciais de Duarte (1987).

18. Dialetalmente, registam-se dados de RC com associado introduzido por para. O Apêndice, no final deste trabalho, reúne exemplos destes casos. 
b. O António fez uma torre de Lego para ele.

- Os complementos oblíquos, mesmo os introduzidos por $a$, não são cliticizáveis (cf. 59b) e podem ser realizados como pronomes fortes não redobrados (cf. 59c). Este novo conjunto de dados mostra que só um $a$-DP (mas não um PP) pode alternar com um clítico dativo e que, à semelhança do caso anterior, uma verdadeira preposição selecionada pelo verbo legitima pronomes fortes não redobrados (neste sentido, (59c) é equivalente a uma frase como Pensámos nele para tratar do assunto):

(59) a. Recorremos a um advogado para tratar do assunto.

b. * Recorremos-lhe para tratar do assunto.

c. Recorremos a ele para tratar do assunto.

Em resumo, a construção de RC em PE verifica a Generalização de Kayne, sendo o associado obrigatoriamente precedido do elemento $a$. Os dados sugerem que este elemento goza de um estatuto ambíguo, funcionando simultaneamente como um marcador/atribuidor de Caso e um marcador de animacidade. A conclusão sobre a sua função exata fica adiada até à secção 3. Defendo que, categorialmente, um associado acusativo ou dativo corresponde sempre a um $a$-DP.

\subsection{Ordem de palavras}

Como se sabe, a distribuição sintática dos pronomes pessoais clíticos em $\mathrm{PE}$ depende da sua qualidade de 'clíticos especiais'. Tomando como hospedeiros categorias verbais, e obedecendo a padróes de colocação sintaticamente condicionados, a posição que um pronome clítico ocupa na frase é distinta da que é ocupada pela contrapartida não clítica do mesmo argumento (embora essa distinção nem sempre seja visível à superfície). Esta assimetria sintática é conhecida e está ilustrada pelo par de frases abaixo: em (60a) o argumento dativo do verbo dizer é realizado pelo $a$-DP ao Pedro em posição final absoluta; em (60b) é realizado pelo clítico the em posição pré-verbal:

(60) a. A Luísa não disse a verdade ao Pedro.

b. A Luísa não lhe disse a verdade.

Sendo a construção de RC caracterizada pela dupla expressão de um argumento através de um clítico e de um $a$-DP associado, há que saber qual é a posição ocupada pelos dois constituintes quando coocorrem na mesma frase. Nesta secção, procurarei mostrar que as posiçôes ocupadas pelo clítico e pelo $a$-DP na configuração de redobro 
são precisamente as mesmas que os dois constituintes ocupam quando ocorrem em distribuição complementar.

Quanto à colocação do clítico, nada há de relevante a dizer, por não ser afetada pela configuração de redobro. Ou seja, os diferentes padrôes de colocação do clítico em PE mantêm-se inalterados e dependentes das condiçóes sintáticas habituais (cf. Martins 2013: 2238).

Quanto ao $a$-DP associado, vou defender (i) que é projetado na posição-A prevista na estrutura sintática para o $a$-DP/DP náo redobrado que lhe corresponde e (ii) que, linearmente, pode ocorrer nas mesmas posiçóes de um $a$-DP/DP não redobrado. Isto não significa que os efeitos discursivos obtidos num e noutro caso sejam coincidentes, questão que discutirei na secção seguinte. Aqui, vou apenas apresentar dois argumentos a favor da hipótese de que o $a$-DP associado é gerado numa posição-A interna a VP.

$\mathrm{O}$ primeiro desses argumentos parte de um diagnóstico originalmente usado para o grego por Sportiche (1996) e replicado, com os mesmos resultados, no espanhol (cf. Franco 2000) e no búlgaro (cf. Harizanov 2014). O objetivo é o de provar que o associado precede material que marca a fronteira direita de VP, não podendo, consequentemente, estar numa posição de adjunção à direita de $\mathrm{VP} / \mathrm{vP}$. Os marcadores da fronteira de VP considerados são completivas de verbos ECM e de verbos de controlo de objeto. Os mesmos testes aplicados ao português mostram que o $a$-DP associado precede esses constituintes:

(61) O professor não $a$ deixou a ela terminar o exame.

(62) O professor permitiu-lhe a ela terminar o exame.

A hipótese de que a ordem de palavras nas frases acima resultasse da extraposição das completivas abriria a possibilidade de que o associado ocupasse uma posição de adjunção à direita de VP/vP. Esta suposição é, no entanto, excluída pela possibilidade de extração a partir das completivas:

(63) O que é que o professor não a deixou a ela terminar?

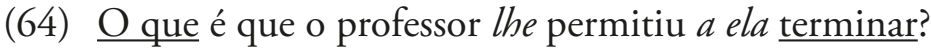

A gramaticalidade de (63)-(64) indica que as completivas em causa não estão deslocadas, o que coloca o associado numa posição interna a VP. Que esta posição interna a VP é uma posiçáo-A é o que pretendo comprovar a seguir.

Este segundo argumento parte da distinção entre a construção de Deslocação à Esquerda Clítica (DEC) e a construção de Deslocação à Esquerda de Tópico Pendente (DETP). Como mostra Duarte (1987), as duas construçóes exibem diferentes graus de sintatização, manifestos, por exemplo, na obrigatoriedade de conetividade casual entre tópico e clítico na DEC, mas não na DETP (cf. 65 vs 66), e na sensibilidade a restriçôes de ilhas na DEC, mas não na DETP (cf. 67 vs 68): 
(65) a. Ao João, a Maria ofereceu-lhe um livro no dia dos anos. (Duarte 2013: 413-414)

b. A este aluno, poucos professores the conhecem as qualidades.

(66) a. O João, a Maria ofereceu-lhe um livro no dia dos anos.

b. Este aluno, poucos professores the conhecem as qualidades.

(67) a. * Ao João, conheço a pessoa [que the deu um livro nos anos].

b. ${ }^{*} A$ este aluno, todos os professores gostam dele, [embora poucos the conheçam as qualidades].

(68) a. O João, conheço a pessoa [que the deu um livro nos anos].

b. Este aluno, todos os professores gostam dele, [embora poucos the conheçam as qualidades].

Os contrastes ilustrados acima levam Duarte (1987) a concluir que a DEC é derivada por movimento do tópico a partir de uma posição interior ao comentário, enquanto na DETP o tópico é gerado na base numa posição de adjunção a uma categoria da periferia esquerda.

Ora, com isto em mente, vejamos como se comportam as duas construçóes face ao RC (mantenho os exemplos de Duarte (2013) para assegurar o paralelismo na exposição, mas os resultados seriam os mesmo com quaisquer outros):

(69) a. * Ao João, a Maria ofereceu-lhe um livro a ele no dia dos anos.

b. ${ }^{*}$ A este aluno, poucos professores the conhecem a ele as qualidades.

(70) a. O João, a Maria ofereceu-lhe um livro a ele no dia dos anos.

b. Este aluno, poucos professores the conhecem a ele as qualidades.

Se assumirmos, como defendo, que, na configuração de redobro, o associado é gerado numa posição-A, o contraste entre (69) e (70) não é inesperado: o redobro é gramatical na DETP, mas não na DEC, porque na DEC o tópico e o associado concorrem para a mesma posição - a posição-A destinada ao argumento que lhes corresponde; já na DEPT, pelo contrário, essa posição está disponível para o associado já que o tópico é gerado na base numa posição de adjunção.

\subsection{Clíticos e pronomes fortes}

Atribui-se a Kayne (1975: 81-92) a primeira sistematização das propriedades que opõem clíticos a pronomes fortes. Entre estas, contam-se duas que são relevantes para o que aqui discutimos: os clíticos, ao contrário dos pronomes fortes, não podem ser coordenados nem focalizados ${ }^{19}$ :

19. Para a relação entre estas propriedades dos clíticos e a construção de RC, veja-se a descrição em 
(71) a. *Vi-os e as na praia.

b. Eles e elas foram vistos na praia.

(72) a. A: O que comeu a Maria?

B:* Comeu-o

b. A: Quem comeu o bolo?

B: Comeu ela.

Cardinaletti \& Starke $(1994,1999)$ propóem que estas duas classes de pronomes têm diferentes níveis de complexidade estrutural/funcional, sendo os clíticos funcionalmente mais deficitários do que os pronomes fortes. De acordo com esta proposta, a escolha entre um e outro tipo de pronomes é orientada por princípios de economia: "where possible, deficient pronouns are preferred over strong ones" (Cardinaletti \& Starke 1999: 160). Assim, a forma forte é excluída nos contextos em que o clítico pode ocorrer; a forma forte é legítima nos contextos em que o clítico é excluído.

Os contrastes de (71) e (72) são facilmente justificados à luz desta proposta: são contextos de exclusão do clítico contextos de coordenação - por violação do requisito de adjacência entre o clítico e o hospedeiro verbal - e contextos de focalização - por incompatibilidade entre a natureza átona do clítico e a proeminência prosódica necessária aos elementos focalizados. Consequentemente, apenas pronomes fortes são admitidos nos exemplos apresentados acima.

Note-se, no entanto, que, para mostrar a diferença de comportamento de clíticos e pronomes fortes em português, contrastei em (71) e (72) dados de coordenação de objeto versus coordenação de sujeito e dados de focalização de objeto versus focalização de sujeito. Vejamos, agora, o que se passa com a coordenação e a focalizaçáo de objetos pronominais. Numa língua como o italiano, que, como vimos na secção 1., não tem RC, tudo se passa conforme o previsto por Cardinaletti \& Starke (1994, 1999): a coordenaçáo e a focalização de objetos pronominais excluem pronomes clíticos e exigem pronomes fortes (cf. (73) e (74), respetivamente). O mesmo não se verifica, contudo, em PE: o que (75) e (76) mostram é que a coordenação e a focalização de objetos pronominais requerem $\mathrm{RC}$, excluindo quer clíticos quer pronomes fortes que ocorram desassociadamente.

(73) a. ${ }^{*}$ Non gli e le dirò mai tutto. (Cardinaletti \& Starke 1999: 166)

não lhe $_{\text {CL.M }}$ e lhe $e_{\text {CL.F }}$ direi mais tudo

b. Non dirò mai tutto a lui $e$ a lei.

náo direi mais tudo a ele $e_{\mathrm{PF} . \mathrm{M}}$ e a ela $\mathrm{PF}_{\mathrm{P} . \mathrm{F}}$

'Nunca lhe direi tudo a ele e/nem a ela.'

Martins (2013: 2237). 
(74) A: Chi hai visto? (Cordin \& Calabrese 1988: 551) 'Quem viste?'

$$
\begin{array}{cl}
\text { B: }{ }^{*} \text { L'ho } & \text { visto. } \\
\mathrm{O}_{\mathrm{CL}} \text {-tenho } & \text { visto } \\
\mathrm{Ho} & \text { visto lui. } \\
\text { tenho } & \text { visto ele }{ }_{\mathrm{PF}} \\
\text { 'Vi-o a ele.' } &
\end{array}
$$

(75) a. ${ }^{*}$ Nunca lhe elnem the direi tudo ${ }^{20}$.

b. * Nunca direi tudo a ele elnem a ela.

c. Nunca lhe direi tudo a ele e/nem a ela.

(76) A: Quem viste?

$$
\begin{aligned}
\mathrm{B}: & * \mathrm{Vi}-o . \\
& * \mathrm{Vi}(\text { a) ele. } \\
& \mathrm{Vi}-o \text { a ele. }
\end{aligned}
$$

Estão, assim, delimitados os contextos de RC em PE: a configuração de redobro emerge sempre que um clítico não pode desempenhar por si só o papel sintático ou discursivo que lhe cabe. Por serem itens lexicais sem acento prosódico atribuído no léxico, não podem realizar constituintes com proeminência focal; por serem clíticos especiais que selecionam a categoria sintática do seu hospedeiro, não podem participar em estruturas de coordenação. Nas subsecções seguintes, descrevo o RC nestes dois contextos.

\subsubsection{Coordenação}

O RC pode envolver a coordenação de dois pronomes, como em (75c) acima, mas também a coordenação de um pronome forte com uma expressão nominal plena (um $a$-DP) (cf. 77). Neste último caso, o pronome corresponde sempre ao primeiro termo coordenado, como mostra a agramaticalidade de (78):

(77) a. O Luís convidou-o a ele e à irmã.

b. O Luís não $o$ convidou a ele nem à irmã.

c. Ou o convido a ele ou à irmá.

20. Procurei manter o paralelismo com o exemplo do italiano, embora o resultado seja especialmente estranho por os clítico dativos em português não terem traços de género. A agramaticalidade do exemplo não decorre, no entanto, desse facto. Os mesmo contrastes se obtêm com clíticos acusativos de $3 .^{a}$ pessoa, marcados para género:
(i) $* \mathrm{Vi}$-o e a na festa.
(ii) * Vi (a) ele e (a) ela na festa.
(iii) Vi-o a ele e a ela na festa. 
d. Não o convidou a ele mas à irmã.

(78) * O João convidou-a à irmã e a ele.

Quer a coordenação envolva dois pronomes, quer envolva um pronome e uma expressão nominal plena, o clítico concorda em número (e, quando aplicável, em género) com o primeiro termo coordenado ${ }^{21}$ :

(79) a. Telefonei-lhe a ele e a ela.

b. ${ }^{*}$ Telefonei-lhes a ele e a ela.

(80) a. Telefonei-lhe a ele e à irmá.

b. *Telefonei-lhes a ele e à irmã.

(81) a. Convidei- $a$ a ela e a ele.

b. * Convidei-os a ela e a ele.

(82) a. Convidei- $a$ a ela e ao irmão.

b. * Convidei-os a ela e ao irmão.

Os factos acima parecem mostrar que da coordenação com RC não resulta uma verdadeira estrutura composta (no sentido de Matos \& Raposo 2013: 1761). Desde logo, porque a irreversibilidade dos termos advém da sua falta de equivalência funcional: como já vimos, em frases como as de (77), a expressão a irmã não poderia ocorrer isoladamente com a função de associado. Para além disso, porque uma estrutura composta que denota uma entidade plural desencadeia concordância plural, ao contrário do que se verifica acontecer em (79)-(82). Relativamente a este último ponto, veja-se que a agramaticalidade de $(79 b)-(82 b)$ não pode decorrer da restrição do $\mathrm{RC}$ a objetos singulares, porque, como sabemos, o fenómeno opera regularmente com objetos plurais simples:

(83) Telefonei-lhes a eles.

(84) Convidei-os a eles.

Concluo, pois, que, em contextos de coordenação, o único associado do clítico é o pronome forte que corresponde ao primeiro termo. Sobre os mecanismos sintáticos que dão origem à coordenação do pronome associado com o $a$-DP que se lhe segue, não tenho nada a dizer neste trabalho ${ }^{22}$.

21. É importante salientar desde já que não são exemplo de RC frases como Telefonei-lhes, a ele e a ela, com pausa depois do clítico e com concordância do clítico com o constituinte composto que se lhe segue. Discutirei esta outra construção na secção 2.6.

22. Perante o paradigma de (79)-(82), um revisor anónimo sugere que o fenómeno de redobro em contextos de coordenação envolva elipse. Segundo a sua hipótese, uma frase como (82a), que aqui repito como (i), seria analisada como mostro em (ii):

(i) Convidei-a a ela e ao irmão. 


\subsubsection{Focalização}

A marcação de um objeto pronominal como foco informacional ou como foco contrastivo requer RC. Assim, por exemplo, no par pergunta/resposta de (76), o que estabelece o valor da variável da interrogativa-QU de objeto é uma expressão pronominal complexa formada pela sequência clítico-associado. Neste contexto, quer o verbo acompanhado pelo clítico, quer o verbo acompanhado pelo pronome forte não constituem respostas bem formadas. O exemplo de (85) repete o mesmo paradigma de (76) desta vez com um objeto dativo:

(85) A: A quem é que o Luís telefonou ontem?

B: * Telefonou-lhe.

* Telefonou a ela.

Telefonou-lhe a ela.

Como se sabe, este é o contexto típico de identificação de foco informacional estreito: corresponde a informação nova o constituinte que fixa o valor da variável representada pelo constituinte-QU da pergunta; neste caso, ao constituinte-QU a quem da pergunta, corresponde a sequência clítico-associado lhe a ela da resposta; a disposição do associado a ela em posição final confere-lhe proeminência prosódica e informacional.

É exatamente por o RC estar associado a uma estratégia discursiva de focalização que uma resposta em que o redobro não corresponda ao constituinte que marca o foco da interrogação é pragmaticamente inadequada:

(86) A: Quando é que o Luís telefonou à Joana?

B: (Telefonou) ontem.

Telefonou-lhe ontem.

\# Telefonou-lhe a ela ontem.

(ii) Convidei-a a ela e eonvidei-o ao irmão.

Afasto esta hipótese com base em dois argumentos. Por um lado, o facto de a contrapartida sem elipse ser agramatical aponta para que a coordenação se dê a um nível mais baixo do que a oração:

(iii) * Convidei-a a ela e convidei-o ao irmão.

Por outro, parece-me que a análise por elipse não permite excluir dados em que as oraçóes coordenadas ocorram na ordem inversa:

(iv) * Convidei-o ao irmão e eonvidei-a a ela.

Veja-se a secção 3. para uma alternativa ao tratamento da coordenação. 
Note-se, contudo, que a resposta que inclui o clítico não redobrado é pragmaticamente natural por o clítico não ser em si mesmo um elemento focalizável, como já vimos.

O mesmo padrão se obtém na marcação de foco contrastivo. $\mathrm{Na}$ conversa simulada em (87), o falante $\mathrm{B}$ expressa discordância relativamente à asserção de $\mathrm{A}$. $\mathrm{O}$ ponto de discórdia incide sobre o argumento tema do predicador levar, que, neste caso, é produzido como um pronome. Neste contexto, novamente se verifica que a focalização sobre o objeto (desta vez para expressar contraste) requer RC, sendo excluídas as alternativas em que o clítico ou o pronome forte ocorrem desassociados. Pelo contrário, o redobro do objeto tema em (88) é sentido como pragmaticamente pouco natural quando a oposição recai sobre outro argumento do predicador ${ }^{23}$ :

(87) A: Com que então o pai levou-te a Paris!

B. * Não. O pai levou- $A$ a Paris, não a mim!

* Não. O pai levou ELA a Paris, náo a mim!

Não. O pai levou-a $A$ ELA a Paris, não a mim!

(88) A: Então mas o pai não levou a Luísa a Londres?

23. Conforme refere um revisor anónimo, é sabido desde Jackendoff (1972) que o foco contrastivo pode recair sobre unidades menores do que a palavra, nomeadamente sobre afixos. Ilustram este facto os seguintes exemplos:

(i) Does Walt UNDERrate the opposition? (Jackendoff 1972: 234) No, he OVERrates it.

(ii) This should be a PREnuptial, not POSTnuptial, agreement! (revisor anónimo)

Dados como estes levam o revisor a pôr a hipótese de ser igualmente possível focalizar contrastivamente um clítico em PE, o que procura fazer no diálogo que transcrevo abaixo:

(iii) A: Falando de Alex, então o pai levou-o a Paris!

B: Levou-A, não O levou, a Paris! Alex é uma menina e não um menino...

Considero, no entanto, que (iii) não é paralelo a (i)-(ii). Os elementos focalizados em (i) e (ii) não são verdadeiros prefixos: são etimologicamente radicais, formam palavras compostas e não derivadas (segundo defendem vários morfólogos), são formas tónicas e gozam de autonomia morfossintática, podendo, por exemplo, ser coordenados:

(iv) Does Walt over- or underrate the opposition?

(v) Is this a pre-or postnuptial agreement?

São estas propriedades que legitimam a sua focalização em contextos comunicacionais neutros, como os de (i) e (ii). Pelo contrário, a focalização de (iii) só é aceitável (e, no meu juízo, dificilmente aceitável) num plano metalinguístico. Com efeito, em (iii), o que está a ser negado e corrigido pelo falante $B$ não é a asserção de $\mathrm{A}$, mas o uso que este faz da forma masculina do clítico. O facto de o clítico poder ser clivado para a obtenção do mesmo efeito (cf. vi) mostra que nestes casos não é um pronome clítico mas um nome que está a ser focalizado, em consequência de um processo de recategorizaçâo, típico do uso metalinguístico:

(vi) A: Falando de Alex, então o pai levou-o a Paris!

B: É 'a' que deves dizer e não 'o'! Alex é uma menina e não um menino... 
B: Não. O pai levou- $a$ A PARIS, não a Londres! \#Náo. O pai levou- a a ela A PARIS, não a Londres!

É também a incapacidade de os clíticos receberem acento prosódico que os torna transparentes na presença de operadores de foco. Assim, numa frase como (89), abaixo, o operador só só pode ter escopo sobre VP e não sobre o objeto clítico, situação que se inverte no caso de o clítico ser redobrado, como em (90):

(89) Eu só $o$ vi;

não the falei.

* não vi a Laura nem a Maria.

(90) Eu só $o$ vi a ele;

\# não lhe falei.

não vi a Laura nem a Maria.

\subsubsection{Uma nota sobre quantificação flutuante e redobro de clítico}

As conclusóes das duas subsecçóes anteriores permitem dizer mais qualquer coisa sobre a relação entre quantificação flutuante $(\mathrm{QF})$ e RC. Na secção 2.1., procurei mostrar que as duas construçôes estáo relacionadas, o que mantenho. Nesta secção, vou evidenciar aquilo em que se distinguem.

Defendi atrás que a construção de $\mathrm{RC}$ envolve sempre um associado pronominal, embora, como vimos, este possa não ter realização fonética nos contextos em que é quantificado (cf. (31)-(32) da secção 2.1.).

Os dados de coordenação póem em evidência esta propriedade do $\mathrm{RC}$, não partilhada pela construção de QF. Assim, considero que a possibilidade de coordenação nas frases com RC em (91) se deve à presença no associado de um pronome oblíquo foneticamente nulo e que é a ausência deste mesmo pronome na construção de QF que impossibilita a coordenação nas frases de (92).

(91) a. Vi-os aos três e à Joana.

b. Vi-os a todos e à Joana.

(92) a. * Vi-os os três e a Joana.

b. *Vi-os todos e a Joana.

Constituem um argumento a favor desta hipótese os padróes de coordenação na formação dos sujeitos compostos de (93)-(94):

(93) a. Eles os três e a Joana foram ao cinema.

b. Eles todos/todos eles e a Joana foram ao cinema. 
(94) a. ?? Os três e a Joana foram ao cinema.

b. * Todos e a Joana foram ao cinema.

Também as conclusôes sobre focalização mostram um contraste entre RC e QF. Embora um quantificador, sendo um item com acento atribuído no léxico, possa ser focalizado, a construção de QF é pragmaticamente menos natural em contextos de focalização de um objeto pronominal do que a contrapartida com RC (cf. 95). Note-se, contudo, que o resultado se inverte quando o foco incide sobre outro constituinte (cf. 96):

(95) A: Quem é que viste na manifestação?

B: \#Vi-os todos. Vi-os a todos.

(96) A: Onde é que viste os miúdos?

B: Vi-os todos na manifestação. \# Vi-os a todos na manifestação.

Mais uma vez, atribuo estes contrastes à presença de um pronome oblíquo foneticamente nulo no RC, inexistente na QF.

Em resumo, defendo que em todos os contextos sintáticos ou discursivos que exigem RC se compóe uma expressão pronominal complexa com o formato clítico-pronome forte. $\mathrm{O}$ facto de este pronome forte poder ser nulo na presença de um quantificador torna as estruturas de RC e de QF superficialmente idênticas. Como veremos, é a diferença da categoria nula quantificada nas duas estruturas que determina o diferente comportamento sintático e os diferentes efeitos discursivos que se manifestam em cada uma.

\subsection{Redobro de Clítico versus Deslocação à Esquerda Clítica e Deslocação à Direita Clítica}

A par do RC, o PE dispóe de outras duas construçóes em que um argumento é duplamente realizado. Neste grupo de construçóes, a duplicação envolve um pronome clítico:

(97) Ofereci-lhe um livro a ele.

(98) A ele, ofereci-lhe um livro.

(99) Ofereci-lhe um livro, a ele.

A frase em (97) instancia a construção de RC até agora descrita. As seguintes são exemplo das construçôes de Deslocação à Esquerda Clítica (DEC) (cf. 98) e de Des- 
locação à Direita Clítica (DDC) (cf. 99). Embora o tipo de duplicação observável nos exemplos acima sugira uma afinidade entre estas construções, são muitas as propriedades que as diferenciam. Ocupo esta secção a identificar algumas delas, mostrando que o $\mathrm{RC}$ se opõe à $\mathrm{DEC}$ e à $\mathrm{DDC}^{24} 25$. As diferenças vão listadas abaixo:

a) Nas construções de DEC e DDC, os constituintes não clíticos podem ser realizados como expressóes nominais/preposicionais plenas (cf. 100), o que, como vimos, não é possível na construção de RC (cf. 101):

(100) a. Ao Pedro, ofereci-lhe um livro.

b. Ofereci-lhe um livro, ao Pedro.

(101)* Ofereci-lhe um livro ao Pedro.

b) Nas construçôes de DEC e DDC, os constituintes não clíticos são realizados na periferia esquerda ou direita da frase, respetivamente, recebem a interpretação de tópicos e são tipicamente produzidos como unidades prosódicas independentes (marcadas por pausa na oralidade e por vírgula em registo escrito) (cf. também Costa 2004: 53):

(102) a. Esse livro, o Pedro leu-o.

b. O Pedro leu-o, esse livro.

(103) a. Ao Pedro, ofereci-lhe o livro.

b. Ofereci-lhe o livro, ao Pedro.

Pelo contrário, na construção de RC, o associado é um elemento interno à frase, recebe tipicamente a interpretação de foco (contrastivo, informacional ou ambos) e não constitui uma unidade prosódica independente. O exemplo (104), com uma fronteira prosódica na posição assinalada, é agramatical como exemplo de RC:

(104) * Ofereci-lhe o livro \# a ele.

c) A Generalização de Kayne (cf. secção 2.3.) não impôe condiçôes às construçôes de DEC e DDC, embora com retomas clíticas acusativas um tópico [+ humano] possa ser opcionalmente introduzido por $a$ (cf. 105). Como vimos, com RC o associado é obrigatoriamente precedido de $a$ (cf. 106):

(105) a. (A)o João, nunca $o$ encontro nas reuniōes.

b. Nunca $o$ encontro nas reuniôes, (a)o João.

24. A caracterização da DEC é baseada em Duarte $(1987,2013)$.

25. Alguns dos contrastes apresentados nesta secção foram já identificados para outras línguas por Anagnostopoulou (2006: 523-530). 
(106) Nunca $o$ encontro ${ }^{*}(a)$ ele nas reunióes.

d) Na construção de DEC, o clítico não pode retomar expressóes quantificadas (cf. 107). Contrastivamente, o RC admite associados com certo tipo de quantificadores (cf. (108) e secção 2.1.):

(107) * Todos eles/todos os colegas, o João convidou-os para a festa.

(108) O Joáo convidou-os a todos/a todos eles para a festa.

e) Nas construçôes de DEC e DDC, tópico e clítico exibem concordância em traços de número e género. Assim, por exemplo, um tópico composto, formado pela coordenação de um termo feminino e um termo masculino, é retomado por um clítico masculino plural (cf. 109). No RC, como se mostrou atrás, o clítico concorda apenas com o primeiro termo coordenado em casos de coordenação (cf. 110):

(109) a. Ela e o marido, conheci-os na inauguração.

b. Conheci-os na inauguraçáo, ela e o marido.

(110) a. Conheci-a a ela e ao marido na inauguração.

b. * Conheci-os a ela e ao marido na inauguraçáo.

f) A construção de DEC está disponível em línguas que não admitem RC. É este o caso do italiano, como mostra o contraste entre a gramaticalidade de DEC em (111) e a agramaticalidade de RC em (112):

(111) a. Giovanni, lo vedo spesso. (Cordin \& Calabrese 1988: 571)

Giovanni o vejo frequentemente

'O Giovanni, vejo-o frequentemente.'

b. A Maria, le mando una lettera spesso.

a Maria lhe mando uma carta frequentemente

'À Maria, mando-lhe uma carta frequentemente'.

(112) a. * Lo vedo Giovanni spesso.

o vejo Giovanni frequentemente

'Vejo o Giovanni frequentemente.'

b. ${ }^{*}$ Le mando una lettera a Maria spesso.

lhe mando uma carta a Maria frequentemente

'Mando uma carta à Maria frequentemente.' 


\section{Análise}

As principais análises formais do fenómeno de $\mathrm{RC}$ podem ser agrupadas em três grandes categorias. Apresento-as abaixo de forma simplificada, procurando descrever a base comum de cada abordagem.

a) O clítico e o associado formam um constituinte único - um DP-grande (bi$g-D P)$-, encabeçado pelo clítico e com o associado na posição de especificador; o DP-grande é gerado como objeto do verbo numa posição-A interna a VP; os mecanismos de cliticizaçáo originam o movimento do clítico, permanecendo o associado na sua posiçáo básica (cf., entre outros, Uriagereka 1995; Torrego 1995, 1998; Cecchetto 2000 e ainda, para uma variante da mesma abordagem, Roberts 2010).

DP-grande

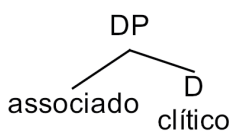

b) O RC é um fenómeno de concordância de objeto, em que o clítico é a manifestação dos traços- $\varphi$ do associado; a concordância estabelece-se ou numa configuração especificador-núcleo, com movimento do associado para o especificador de um núcleo funcional verbal ou, na fase pós Chomsky (2000, 2001), numa relação de Agree entre o núcleo funcional (probe) e o associado (goal); em ambos os casos, o clítico é o spell-out de um núcleo funcional após validação dos traços- $\varphi$ (cf., entre outros, Borer 1984; Suñer 1988; Sportiche 1996; Franco 2000; Franks \& King 2000; Morais 2006; Anagnostopoulou 2016).

(114) Concordância de objeto (por Agree)

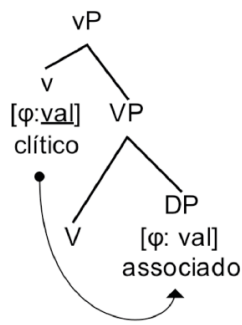


c) O RC é o resultado do movimento/cópia do associado para uma posição no domínio funcional de VP (geralmente, a posição de especificador de vP para satisfação de um traço EPP de v), seguido de uma operação de redução da cópia mais alta gerada pelo movimento; a operação de redução tem o efeito de reduzir o DP associado, apagando todo o material de que é composto exceto o núcleo $\mathrm{D}$; a cliticização da cópia reduzida produz-se por meio de diferentes versóes da operação m-merger proposta por Matushansky (2006) (cf. Kramer 2014; Harizanov 2014; Van Urk 2015; Baker \& Kramer 2016).
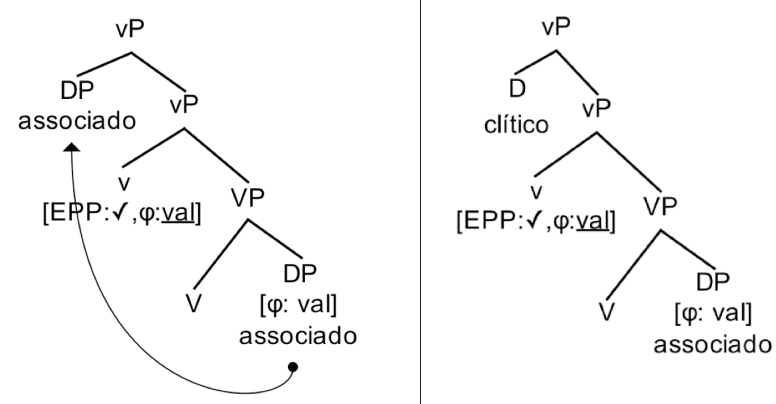

A aplicação de qualquer destas análises ao PE revela-se problemática por nenhuma captar o padrão de RC observado nesta língua: a impossibilidade de redobro com DPs plenos e a obrigatoriedade de redobro com pronomes fortes ${ }^{26}$.

A origem desta dificuldade está, segundo creio, num problema de perspetiva. Em todas as análises apresentadas acima (talvez à exceção das análises de tipo (a)), o clítico é sempre interpretado como um duplo do associado, ou seja, o clítico, em resultado de diferentes mecanismos, é a manifestação reduzida do associado. Contudo, as propriedades do RC em PE, apresentadas na secção 2., sugerem que o redobro nesta língua (e provavelmente em francês) se dá em sentido inverso. Concretizando, em PE, o associado só emerge nos contextos sintáticos ou discursivos em que o clítico não tem capacidade de desempenhar por si só o papel que lhe cabe. Neste sentido, o associado é o duplo (obrigatório) do clítico.

A visão do redobro do português como um fenómeno de "último recurso" permite, de algum modo, relacioná-lo com o Avoid Pronoun Principle (APP), informal-

26. Na verdade, a adaptação da proposta de Baker \& Kramer (2016) ao PE pode ser uma hipótese a explorar. Os próprios autores chegam a sugerir que uma língua que não disponha da operação de redução só poderá ter $\mathrm{RC}$ com categorias $\mathrm{X}^{\mathrm{o}} / \mathrm{X}^{\max }$, o que poderá ser o caso dos pronomes fortes em PE. Deixo para trabalho futuro a maturação desta ideia. Diercks \& Sikuku (2013) desenvolvem uma proposta nesta linha para o lubukusu. 
mente formulado em Chomsky (1981: 65) ${ }^{27}$. Com efeito, N. Chomsky exclui frases como as de (117) com base no facto de estarem disponíveis frases como (116):

(116) John would much prefer PRO going to the movie. (Chomsky 1981: 64-65)

(117) ?? John $n_{i}$ would much prefer his ${ }_{i}$ going to the movie.

Nas suas próprias palavras, o APP é "interpreted as imposing a choice of PRO over an overt pronoun where possible" (Chomsky 1981: 65, sublinhado meu). Mas é o "where possible" que aqui nos interessa: o próprio Chomsky (1981: 142, nota 45) alerta para o facto de a frase em (117) se tornar gramatical com enfáticos reflexos:

(118) John $_{\mathrm{i}}$ would much prefer his ${ }_{\mathrm{i}}$ going to the movie himself.

Na construção ACC-ing, observam-se os mesmos contrastes:

(119) Harry hates PRO kissing Mary. (Hornstein 2006: 64-65)

(120) * Harry ${ }_{\mathrm{i}}$ hates him kissing Mary.

(121) Harry hates HIMSELF kissing Mary.

Conclui-se daqui que é possível ou, aliás, obrigatório realizar um sujeito pronominal correferente do sujeito matriz sempre que este recebe acento focal. Assim, por exemplo, uma frase como (121) é uma frase natural no contexto da refutação abaixo, em que o pronome reflexo é contrastivamente focalizado:

(122) A: Harry hates John kissing Mary. B: No. Harry hates HIMSELF kissing Mary.

Como é evidente, a realização do pronome correferente é igualmente obrigatória nos casos em que este se encontra coordenado com outro constituinte:

(123) * Harry hates PRO and his friends kissing Mary.

(124) Harry hates himself and his friends kissing Mary.

Isto permite estabelecer um paralelo interessante com os casos de RC em PE que discuti atrás. Também aí, como aqui, um pronome correferente se manifesta se e só se as contrapartidas sem pronome forem excluídas; também aí, como aqui, os contextos de exclusão são contextos de focalização e coordenação.

27. Agradeço a um revisor anónimo ter-me feito notar esta relação. 
Com isto em mente, vou propor que na construção de RC em PE o associado seja um pronome enfático, no sentido originalmente proposto por Burzio (1986) ${ }^{28}$. Concretamente, defendo que o associado é a realização da cópia criada pelo movimento do clítico para satisfação de um requisito em PF. A proposta alinha-se da seguinte forma:

- O objeto pronominal das frases com RC entra na numeração como um clítico. A escolha do clítico sobre o pronome forte é motivada ou por princípios de economia (o clítico é um elemento funcionalmente defetivo, correspondendo apenas ao conteúdo flexional da estrutura de um pronome; Cardinaletti \& Starke 1994, 1999; Roberts 2010), ou, se considerarmos que os clíticos são marcados para Caso, por ação da Elsewhere Condition ou variantes (Kiparsky 1973; Lasnik 1981; Lumsden 1992; Halle \& Marantz 1993; Raposo 1998);

- O clítico ( $\varphi$ P ou DP) é projetado como objeto do verbo numa posição argumental interna a $\mathrm{VP}^{29}$;

- Os clíticos objeto das línguas românicas são inerentemente específicos e definidos (Uriagereka 1995; Sportiche 1996);

- v está associado a um traço EPP relativo à interpretação específica do objeto que atrai categorias mínimas (Chomsky 2001; Roberts 2010; Baker \& Kramer 2016);

- O clítico move-se para a posição de [Spec, vP] para satisfação do traço EPP de v (os clíticos têm um estatuto categorial ambíguo sendo simultaneamente categorias máximas e mínimas (Muysken 1982) e, como tal, podem mover-se quer como XPs, quer como núcleos (Sportiche 1996; Barbosa 2000; Costa \& Martins 2003, 2004; Matushansky 2006; Roberts 2010);

28. A noção de pronome enfático foi introduzida por Burzio (1986) a propósito do redobro de sujeito que se manifesta em infinitivas de controlo (cf. i) e em construçôes mono-oracionais (cf. ii) nas línguas românicas de sujeito nulo:

(i) A Teresa decidiu escrever ela o poema. (Barbosa 2009: 107-110)

(ii) A Teresa / ela escreveu ela o poema (ninguém a ajudou).

Na proposta de Burzio (1986), o pronome enfático foi analisado como a realização do vestígio do sujeito movido. $\mathrm{O}$ fenómeno tem recebido desde entâo grande atenção na literatura e as análises mais recentes afastam-se da abordagem original. Para o português, o trabalho fundamental sobre este tópico é o de Barbosa (2009). Vejam-se as referências indicadas nesse trabalho sobre o mesmo fenómeno noutras línguas, em especial Belletti (2005), que também aproxima o redobro de sujeito do RC, propondo que o sujeito pré-verbal e o pronome enfático são gerados como um DP-grande, do tipo que descrevi no início desta secção.

29. Como vimos na secção 2.2., os dativos de posse ou os dativos benefactivos não argumentais são gerados internamente ao DP-tema selecionado pelo verbo, o que os coloca igualmente numa posição interna a VP (Miguel, Gonçalves \& Duarte 2011). 
- $\mathrm{O}$ traço de especificidade que origina o movimento do clítico para [Spec, vP] tem um efeito de desfocalização (cf. o contraste entre lo conosco / conosco LUI assinalado por Roberts 2010: 48, apud Adam Ledgeway, c.p.);

- A cópia originada pelo movimento do clítico é produzida para satisfação de um requisito em PF: receber acento prosódico neutro numa posição da margem direita da frase (foco informacional) ou receber acento prosódico marcado quando está associada ao traço [+ contrast] (foco contrastivo) (Ortega-Santos 2006; Stjepanovic 2007);

- As duas cópias da cadeia não são isomórficas devido à formação de um núcleo complexo através de m-merger entre clítico e v (cf. hipótese de incorporação de Roberts 2010) ou de m-merger entre o clítico e V+T (Costa \& Martins 2003, 2004; Matushansky 2006), o que torna possível a linearização (Nunes 2004);

- A cópia mais baixa da cadeia é produzida sob a forma de um pronome forte oblíquo que realiza os traços- $\varphi$ do clítico e que é marcado Casualmente pelo elemento $a$, inserido numa fase tardia para salvar a derivação (cf. Generalização de Kayne; Jaeggli 1982). O pronome forte é opcionalmente realizado no caso de ser quantificado, já que a presença do quantificador assegura o conteúdo fonológico da cópia mais baixa para atribuição de acento prosódico.

Para além de captar as propriedades da construção de RC em PE que apresentei na secção 2., considero que esta linha de análise traz ainda as seguintes vantagens:

- Se o clítico e o associado corresponderem a uma única categoria, o fenómeno de RC não coloca um desafio ao Princípio de Interpretação Plena ou ao Princípio de Economia da Representação (Chomsky 1986a, 1995);

- Relacionar o clítico e o associado por movimento permite satisfazer o Critério Temático (é atribuído um único papel- $\theta$ à cadeia de movimento) (Chomsky 1986b) e a Teoria da Ligação (segundo Burzio 1986, os pronomes enfáticos são categorialmente pronomes, mas funcionalmente anáforas, o que explica que uma configuração de RC não viole o Princípio B) (Chomsky 1981);

- O facto de o redobro só ocorrer com quantificadores que admitem flutuação fica explicado por a derivação da construção de RC com pronomes quantificados e a da construção de QF de objeto serem comuns até uma fase tardia. Ou seja, em ambos os casos há um objeto pronominal quantificado com uma estrutura interna que permite o movimento sintático do clítico para [Spec, vP] 
e a flutuação do quantificador. Defendo, pois, que frases como as de (51), aqui repetidas como (125), tenham exatamente a mesma numeração e a mesma derivação na componente sintática:

(125) a. Vi-os todos na manifestação.

b. Vi-os a todos na manifestação.

É na componente pós-sintática, em PF, que a derivação das duas construçóes diverge: $a$ é inserido na construção de RC em (125b), mas não na construção de QF em (125a). Este passo torna distintas as categorias quantificadas nos dois contextos: na configuração de redobro a categoria quantificada é um pronome forte, Casualmente marcado, necessariamente [+ animado/humano], que pode ser realizado ou nulo (pro); na configuração de QF, a categoria quantificada é o vestígio (ou a cópia nula) do movimento do clítico, sem marcação Casual e sem especificação (obrigatória) do traço semântico de animacidade. Esta diferença é responsável pelos contrastes ilustrados abaixo, relativos à possibilidade de realização da categoria quantificada (cf. 126) e à interpretação do objeto pronominal (cf. 127), e, concomitantemente, responsável pelos contrastes sintáticos e discursivos discutidos na secção 2.5.3.

(126) a. * Vi-os eles todos na manifestação.

b. Vi-os a eles todos na manifestação.

(127) a. $\mathrm{Vi}$-os todos na manifestação. $\quad[\checkmark$ os = cartazes; $\checkmark$ os $=$ miúdos $]$

b. Vi-os a todos na manifestação. [ ${ }^{*}$ os $=$ cartazes; $\quad \sqrt{o s}=$ miúdos $]$

- A inserção de $a$ em PF para atribuição de Caso e convergência da derivação permite redefinir o estatuto de $a$ no que diz respeito à questáo da animacidade. $\mathrm{Na}$ verdade, se $a$ impusesse restriçóes de seleção relativas a animacidade, seria estranho que só o fizesse em contextos de redobro, visto que noutros contextos nada de semelhante se verifica (cf. 129):

(128) a. Já não há biscoitos de aveia, que eu comi-os todos.

b. * Já não há biscoitos de aveia, que eu comi-os a todos.

(129) Fiz biscoitos de aveia, mas queimei as pontas a todos.

Porém, à luz desta hipótese, a animacidade do associado não depende da presença de $a$, sendo apenas um efeito colateral do Caso oblíquo que $a$ lhe atribui, visto que uma forma pronominal oblíqua é tipicamente dotada do traço [+ hu- 
mano $]^{30}$. Assim, RC e animacidade estão efetivamente correlacionados em PE, mas não é o elemento $a$ que estabelece diretamente essa correlação. Ou seja, $a$ não impóe restriçôes de seleção semântica ao associado nem é a expressão dos traços semânticos do associado. Adota-se aqui a visão clássica da Generalização de Kayne, em que $a$ é entendido como um atribuidor de Caso. Em PE, o Caso é atribuído à cópia mais baixa do clítico de forma a torná-la visível em PF;

- O facto de clítico e pronome forte serem entendidos como duas cópias do mesmo objeto justifica os fenómenos de concordância e ordem de palavras em estruturas coordenadas discutidos na secção 2.5.1. Com efeito, esta proposta faz, no que respeita à coordenação, duas importantes prediçóes: a primeira é a de que a partilha de traços- $\varphi$ entre os dois elementos da cadeia levará à concordância do clítico apenas com o primeiro termo coordenado; a segunda é a de que a realização do pronome na posição de origem do clítico o colocará invariavelmente na periferia esquerda da estrutura coordenada, ou seja, na posiçáo de primeiro termo coordenado, a única que legitima a extração do clítico. Ambas as prediçóes são empiricamente sustentadas. Note-se que, pelo contrário, se o $\mathrm{RC}$ em PE fosse analisado como um fenómeno de concordância de objeto, o clítico seria necessariamente plural nos casos de redobro de um objeto composto, o que não se confirma;

- Se clítico e associado correspondem a duas cópias de uma mesma categoria projetada na posição básica de um DP objeto, prediz-se que não será possível extrair um operador dessa mesma posição, o que se verifica acontecer em PE: o clítico não pode redobrar um operador interrogativo que liga uma variável (cf. 130). Contrastivamente, estas construçôes são legítimas em línguas como o espanhol (cf. 131) e o romeno (cf. 132), línguas para as quais têm sido propostas quer análises em que clítico e associado entram na numeraçáo como duas categorias distintas projetadas em posiçôes estruturais diferenciadas (análises do tipo (a), esquematizadas em (113)), quer análises em que o clítico é apenas um marcador de concordância de objeto e náo um verdadeiro pronome (análises do tipo (b), esquematizadas em (114)). Em qualquer destas propostas, nada impede que o associado corresponda a um operador interrogativo que liga uma variável em posição básica ${ }^{31}$.

30. Com efeito, os pronomes de $1 .^{\mathrm{a}}$ e $2 .^{\mathrm{a}}$ pessoa, dada a sua natureza dêitica, estão associados ao traço [+ humano] em todas as formas casuais; os pronomes de $3 .{ }^{\text {a }}$ pessoa são [ \pm humano] nas formas acusativas e dativas, mas tipicamente [+ humano] nas formas nominativas e oblíquas.

31. A este respeito, é ainda de salientar que as análises do tipo (c), esquematizadas em (115), nas quais clítico e associado também formam uma cadeia de movimento (neste caso, por cópia e redução), têm sido propostas para línguas como o Amárico, que, previsivelmente, se comporta neste aspeto como o PE: 
(130) a. * A quem the ofereceram um carro?

b. * A quem the tens enviado dinheiro?

(131) ¿A quien le regalaron un auto?

(Suñer 1988: 391)

a quem the ofereceram um carro

'A quem ofereceram um carro?'

(132) Cui $i$-ai trimis bani? (Dobrovie-Sorin 1990: 355)

quem $_{\text {DAT }}$ lhe-tens enviado dinheiro

'A quem tens enviado dinheiro?'

\section{Conclusões}

Este artigo propunha-se investigar a construção de RC em PE. A análise comparada deste fenómeno revelou que o padráo de redobro nesta língua a distanciava (em conjunto com o francês) das restantes línguas românicas, bem como, tanto quanto sei, de todas as línguas de redobro (cf. nota 2). No espaço românico, duas propriedades tornavam único o paradigma de RC do PE: (i) a categoria do associado - necessariamente um pronome forte - distinguia o PE do espanhol e do romeno e (ii) a emergência obrigatória da configuração de redobro em contextos que excluíam a ocorrência dissociada quer do clítico quer do pronome forte distinguia o PE do italiano. Estes dois fatores sugeriam que na base deste fenómeno em PE estava uma propriedade que liga clíticos a pronomes fortes - a categoria - e uma propriedade que opóe clíticos a pronomes fortes $-\mathrm{o}$ acento.

$\mathrm{Na}$ análise que apresento, clítico e pronome forte estáo associados por movimento e a configuração de redobro resulta da produção das duas cópias da cadeia de movimento para satisfação de um requisito em PF. O RC é, nesta perspetiva, um fenómeno de interface que envolve duas operaçôes independentemente motivadas: o movimento sintático do clítico para satisfação de um traço EPP de v (e cliticização ao hospedeiro verbal) e a realização do pronome forte em PF para atribuição de acento prosódico. Considero que uma análise como esta, que trata o RC do PE como um fenómeno de interface entre a sintaxe e PF, parece ser adequada para a compreensão da especificidade da construção nesta língua: relacionar clítico e associado por movimento sintático capta a sua identidade categorial; interpretar o redobro como o spell-out das duas cópias da cadeia por um requisito de atribuição de acento capta a sua distinção fonológica.

(i) Almaz lä-man gänzäb sät't'-ät $\int \mathrm{t} \int-i w$ ? (Baker \& Kramer 2016: 36)
Almaz quem
'A dinheiro dá duem dá Almaz dinheiro?' 
Note-se, no entanto, que entendo esta abordagem adequada aos dados particulares de redobro do PE, podendo eventualmente ser estendida aos dados do francês. Nesta perspetiva, o termo 'redobro de clítico' é um termo meramente descritivo que pode corresponder em diferentes línguas a diferentes construçóes, que envolvem diferentes operaçóes em diferentes componentes da gramática. Se é possível que no interior de uma mesma língua coexistam vários tipos de $\mathrm{RC}$ é uma questão a investigar. Se assim for, talvez o redobro pronominal obrigatório do espanhol e do romeno esteja mais próximo do do PE do que do redobro de DPs plenos que se manifesta igualmente nessas línguas. 


\section{Referências bibliográficas}

Adger, David \& Daniel Harbour. 2007. Syntax and syncretisms of the Person Case Constraint. Syntax 10(1), 2-37. https://doi.org/10.1111/j.1467-9612.2007.00095.x.

Anagnostopoulou, Elena. 1994. Clitic Dependencies in Modern Greek. Salzburg University. (Tese de doutoramento inedita).

Anagnostopoulou, Elena. 2006. Clitic Doubling. Em Martin Everaert \& Henk van Riemsdijk (eds.), Blackwell Companion to Syntax. 519-580. Malden, MA: Blackwell. https://doi. org/10.1002/9780470996591.ch14.

Anagnostopoulou, Elena. 2016. Clitic doubling and object agreement. Em Susann Fischer \& Mario Navarro (eds.), Proceedings of the VII Nereus International Workshop: Clitic Doubling and other issues of the syntax/semantic interface in Romance DPs (Arbeitspapier, 128). 11-42. Konstanz: Fachbereich Sprachwissenschaft der Universität Konstanz. https://kops.uni-konstanz.de/handle/123456789/35916.

Aoun, Joseph. 1999. Clitic-Doubled Arguments. Em Kyle Johnson \& Ian Roberts (eds.), Beyond Principles and Parameters: Essays in Memory of Osvaldo Jaeggli. 13-42. Dordrecht: Kluwer. https://doi. org/10.1007/978-94-011-4822-1_2.

Baker, Mark \& Ruth Kramer. 2016. Doubling Clitics are Pronouns: Reduce and Interpret. Rutgers University - Georgetown University. (Ms).

Barbosa, Pilar. 2000. Clitics: A window into the null subject property. Em João Costa (ed.), Portuguese Syntax. New comparative studies. 31-93. New York: Oxford University Press.

Barbosa, Pilar. 2009. A case for an Agree-based theory of control. Em Sun-Woong Kim (ed.), 11th Seoul international conference on generative grammar proceedings. 101-123. Seoul: Hankuk.

Belletti, Adriana. 2005. Extended doubling on the VP periphery. Probus 17(1), 1-35. https://doi. org/10.1515/prbs.2005.17.1.1.

Boneh, Nora \& Léa Nash. 2009. A higher applicative: Evidence from French. Em Yehuda Falk (ed.), Proceedings of IATL 25, 1-21. Israel Association for Theoretical Linguistics. http://linguistics.huji. ac.il/IATL/25/Boneh_Nash.pdf

Borer, Hagit. 1984. Parametric syntax, case studies in Semitic and Romance languages. Dordrecht: Foris Publications.

Braga, Rafael. 2016. Cliticização e redobro de clíticos pronominais em kayabi (tupi-guarani, Tupi): A natureza ambigua de constituintes cliticos. Universidade Federal do Rio de Janeiro. (Tese de doutoramento inédita). http://www.etnolinguistica.org/tese:braga-2016.

Brito, Ana Maria. 2009. Construçôes de objecto indirecto preposicionais e não preposicionais: Uma abordagem generativo-constructivista. Em Alexandra Fiéis \& Maria Antónia Coutinho (eds.), Textos seleccionados. XXIV Encontro da Associação Portuguesa de Linguística. 141-159. Lisboa: APL - Colibri.

Burzio, Luigi. 1986. Italian Syntax: A Government-Binding Approach. Dordrecht: Reidel. 10.1007/97894-009-4522-7.

Cardinaletti, Anna \& Michal Starke. 1994. The Typology of Structural Deficiency. On the Three Grammatical Classes. Working Papers in Linguistics 4(2), 41-109. 
Cardinaletti, Anna \& Michal Starke. 1999. The typology of structural deficiency: A case study of the three classes of pronouns. Em Frits Beukema \& Marcel den Dikken (eds.), Clitics in the languages of Europe. 145-233. Berlin: Mouton de Gruyter. http://hdl.handle.net/10278/10562

Caskey, Alexander F. 1979. An edition, study, and glossary of the Old Portuguese translations of Partidas I \& III of the Alfonsine Siete Partidas. University of Wisconsin-Madison. (Tese de doutoramento inédita).

Castro, Ivo. 1984. Livro de José de Arimateia (Estudo e Edição do COD. ANTT 643). Universidade de Lisboa. (Tese de doutoramento inedita).

Cecchetto, Carlo. 2000. Doubling structures and reconstruction. Probus 12(1), 93-126. https://doi. org/10.1515/prbs.2000.12.1.93.

Chomsky, Noam. 1981. Lectures on Government and Binding. Dordrecht: Foris.

Chomsky, Noam. 1986a. Knowledge of language: Its nature, origin, and use. New York: Praeger.

Chomsky, Noam. 1986b. Barriers. Cambridge, MA: MIT Press.

Chomsky, Noam. 1995. The Minimalist Program. Cambridge, MA: MIT Press. 10.7551/mitpress/9780262527347.001.0001

Chomsky, Noam. 2000. Minimalist inquiries: The framework. Em Roger Martin, David Michaels \& Juan Uriagereka (eds.), Step by step: Essays on minimalist syntax in honor of Howard Lasnik. 89155. Cambridge, MA: MIT Press.

Chomsky, Noam. 2001. Derivation by phase. Em Michael Kenstowicz (ed.), Ken Hale: A Life is Language. 1-52. Cambridge, MA: MIT Press.

Cintra, Luís Filipe Lindley. 1951. Crónica geral de Espanha de 1344. Edição crítica do texto português. Lisboa: Academia Portuguesa da História.

Cordin, Patrizia \& Andrea Calabrese. 1988. I pronomi personali. Em Lorenzo Renzi, Giampaolo Salvi \& Anna Cardinaletti (eds.), Grande grammatica italiana di consultazione. 549-606. Bologna: Il Mulino.

Costa, João \& Ana Maria Martins. 2003. Clitic Placement across grammar components. Comunicação apresentada em Going Romance, Nijmegen University.

Costa, João \& Ana Maria Martins. 2004. What is a strong functional head? Comunicação apresentada em Lisbon workshop on alternative views to the functional domain, Universidade Nova de Lisboa.

Costa, João. 2004. Subject Positions and Interfaces: The case of European Portuguese. Berlin - New York: Walter de Gruyter.

Cuervo, María Cristina. 2003. Datives at large. Massachusetts Institute of Technology. (Tese de doutoramento inedita). http://hdl.handle.net/1721.1/7991

Demonte, Violeta. 1995. Dative Alternation in Spanish. Probus 7, 5-30. https://doi.org/10.1515/ prbs.1995.7.1.5.

Diercks, Michael \& Justine Sikuku. 2013. Object clitics in a Bantu language: Deriving pronominal incorporation in Lubukusu. Pomona College - Moi University. (Ms).

Dobrovie-Sorin, Carmen. 1990. Clitic Doubling, Wh-Movement, and Quantification in Romanian. Linguistic Inquiry 21(3), 351-397. http://www.jstor.org/stable/4178681.

Duarte, Inês. 1987. A construção de topicalização na gramática do português: regência, ligação e condiçóes sobre movimento. Universidade de Lisboa. (Tese de doutoramento inédita). 
Duarte, Inês. 2003. Relaçóes gramaticais, esquemas relacionais e ordem de palabras. Em Mateus, Maria Helena Mira, Ana Maria Brito, Inês Silva Duarte \& Isabel Hub Faria (eds.), Gramática da Lingua Portuguesa. 275-321. Lisboa: Caminho.

Duarte, Inês. 2013. Construções de topicalização. Em Eduardo Buzaglo Paiva Raposo, Maria Fernanda Bacelar do Nascimento, Maria Antónia Coelho da Mota, Luísa Segura \& Amália Mendes (coord.), Gramática do Português. vol. I. 400-426. Lisboa: Fundação Calouste Gulbenkian.

Enç, Murvet. 1991. The Semantics of Specificity. Linguistic Inquiry 22(1), 1-27. http://www.jstor.org/ stable/4178706.

Everett, Daniel. 1987. Pirahã Clitic Doubling. Natural Language and Linguistic Theory 5(2), 245-276. https://doi.org/10.1007/BF00166586.

Ferreira, José de Azevedo. 1987. Afonso X- Foro Real. Ediçâao, estudo linguístico e glossário. Lisboa: INIC.

Fischer, Susann \& Esther Rinke. 2013. Explaining the variability of clitic doubling across Romance: a diachronic account. Linguistische Berichte 236, 455-472.

Franco, Jon. 2000. Agreement as a continuum: The case of Spanish pronominal clitics. Em Frits Beukema \& Marcel den Dikken (eds.), Clitic Phenomena in European Languages. 147-190. Amsterdam, Philadelphia: John Benjamins. https://doi.org/10.1075/la.30.07fra

Franks, Steven \& Tracy King. 2000. A handbook of Slavic clitics. New York: Oxford University Press.

Franks, Steven. 2009. Macedonian pronominal clitics as object agreement markers. Em Steven Franks, Vrinda Chidambaram \& Brian Joseph (eds.), A linguist's linguist: Studies in South Slavic linguistics in honor of E. Wayles Browne. 189-222. Bloomington, IN: Slavica. http://muse.jhu.edu/chapter/718067

Gonçalves, Anabela \& Eduardo Paiva Raposo. 2013. Verbo e sintagma verbal. Em Eduardo Buzaglo Paiva Raposo, Maria Fernanda Bacelar do Nascimento, Maria Antónia Coelho da Mota, Luísa Segura \& Amália Mendes (coord.), Gramática do Português, vol. II. 1155-1218. Lisboa: Fundação Calouste Gulbenkian.

Gonçalves, Perpétua. 1990. A Construção de uma Gramática do Português em Moçambique: Aspectos da Estrutura Argumental dos Verbos. Universidade de Lisboa. (Tese de doutoramento inédita).

Gonçalves, Rita. 2015. Romance languages do not have double objects: Evidence from European Portuguese and Spanish. Estudos de Lingüistica Galega 7, 53-67. http://dx.doi.org/10.15304/ elg.7.2337.

Halle, Morris \& Alec Marantz. 1993. Distributed Morphology and the Pieces of Inflection. Em Keneth Hale \& Samuel Jay Keyser (eds.), The view from Building 20: Essays in linguistics in honor of Sylvain Bromberger. 111-176. Cambridge, MA: MIT Press.

Harizanov, Boris. 2014. Clitic doubling at the syntax-morphophonology interface: A-movement and morphological merger in Bulgarian. Natural Language \& Linguistic Theory 32(4), 1033-1088. https://doi.org/10.1007/s11049-014-9249-5.

Hornstein, Norbert. 2006. Pronouns in a Minimalist Setting. Em Nina Kazanina, Utako Minai, Philip J. Monahan \& Heather L. Taylor (eds.), University of Maryland Working Papers in Linguistics 14. 47-80. College Park, MD: UMWPiL.

Jackendoff, Ray. 1972. Semantic Interpretation in Generative Grammar. Cambridge, MA: MIT Press.

Jaeggli, Osvaldo. 1982. Topics in Romance Syntax. Dordrecht: Foris. https://doi.org/10.1075/ li.9.1.11 roo 
Kallulli, Dalina \& Liliane Tasmowski (eds.). 2008a. Clitic Doubling in the Balkan Languages. Amsterdam: John Benjamins. https://doi.org/10.1075/la.130

Kallulli, Dalina \& Liliane Tasmowski. 2008b. Clitic doubling, core syntax and the interfaces. Em Dalina Kallulli \& Liliane Tasmowski (eds.), Clitic doubling in the Balkan languages. 1-32. Amsterdam: John Benjamins. https://doi.org/10.1075/la.130.03kal

Karttunen, Lauri. 1976. Discourse Referents. Em James McCawley (ed.), Syntax and Semantics 7: Notes from the Linguistic Underground. 363-385. New York: Academic Press.

Kayne, Richard. 1975. French syntax: The transformational cycle. Cambridge, MA: MIT Press. http:// hdl.handle.net/2027/heb.08434.0001.001

Kayne, Richard. 2000. Parameters and universals. New York: Oxford University Press.

Kiparsky, Paul. 1973. 'Elsewhere' in Phonology. Em Steven Anderson \& Paul Kiparsky (eds.), A Festschrift for Morris Halle. 11-49. New York: Holt, Rinehart \& Winston.

Kramer, Ruth. 2014. Clitic doubling or object agreement: the view from Amharic. Natural Language and Linguistic Theory 32(2), 593-634. https://doi.org/10.1007/s11049-014-9233-0.

Lasnik, Howard. 1981. Restricting the theory of transformations: A case study. Em Norbert Hornstein \& David Lightfoot (eds.), Explanation in linguistics. 152-173. London: Longman.

Lumsden, John. 1992. Underspecification in Grammatical and Natural Gender. Linguistic Inquiry 23(3), 469-486. http://www.jstor.org/stable/4178781.

Martins, Ana Maria. 1994. Clíticos na história do português. Universidade de Lisboa. (Tese de doutoramento inédita).

Martins, Ana Maria. 2001. Documentos portugueses do Noroeste e da regiáa de Lisboa. Da produção primitiva ao século XVI. Lisboa: IN-CM.

Martins, Ana Maria. 2013. A posição dos pronomes pessoais clíticos. Em Eduardo Buzaglo Paiva Raposo, Maria Fernanda Bacelar do Nascimento, Maria Antónia Coelho da Mota, Luísa Segura \& Amália Mendes (coord.), Gramática do Português, vol. II. 2231-2302. Lisboa: Fundação Calouste Gulbenkian.

Martins, Ana Maria. 2016. Introdução: O português numa perspetiva diacrónica e comparativa. Em Ana Maria Martins \& Ernestina Carrilho (eds.), Manual de Linguística Portuguesa. 1-40. Berlin, Boston: De Gruyter. http://hdl.handle.net/10451/31206

Matos, Gabriela \& Eduardo Paiva Raposo. 2013. Estruturas de coordenaçáo. Em Eduardo Buzaglo Paiva Raposo, Maria Fernanda Bacelar do Nascimento, Maria Antónia Coelho da Mota, Luísa Segura \& Amália Mendes (coord.), Gramática do Português, vol. II. 1759-1817. Lisboa: Fundação Calouste Gulbenkian.

Matos, Gabriela. 2003. Tipologia dos pronomes clíticos. Em Mateus, Maria Helena Mira, Ana Maria Brito, Inês Silva Duarte \& Isabel Hub Faria (eds.), Gramática da Lingua Portuguesa. 826-847. Lisboa: Caminho.

Matushansky, Ora. 2006. Head movement in linguistic theory. Linguistic Inquiry 37(1), 69-109. https://doi.org/10.1162/002438906775321184.

Michelioudakis, Dimitris \& Eleni Kapogianni. 2013. Ethical Datives: A puzzle for syntax, semantics, pragmatics, and their interfaces. Em Raffaella Folli, Christina Sevdali \& Robert Truswell (eds.), Syntax and its limits. 345-369. New York: Oxford University Press. https://doi.org/10.1093/ acprof:oso/9780199683239.003.0017 
Miguel, Matilde, Anabela Gonçalves \& Inês Duarte. 2011. Dativos não argumentais em portugués. Em Armanda Costa, Pilar Barbosa \& Isabel Falé (eds.), Textos seleccionados. XXVI Encontro da Associação Portuguesa de Linguistica. 388-400. Lisboa: APL.

Morais, Maria Aparecida. 2006. Argumentos dativos: Um cenário para o núcleo aplicativo no português europeu. ABRALIN 5(1-2), 239-266. http://dx.doi.org/10.5380/rabl.v5i1/2.52647.

Muysken, Pieter. 1982. Parametrizing the notion "head'. Journal of Linguistic Research 2(3), 57-75. http://hdl.handle.net/2066/14544.

Nunes, Jairo. 2004. Linearization of Chains and Sideward Movement. Cambridge, MA: MIT Press.

Oliveira, Fátima. 1987. Cadeias anafóricas: que referência? Revista da Faculdade de Letras: Linguas e Literaturas II(4), 125-136.

Ortega-Santos, Iván. 2006. On New Information Focus, Sentence Stress Assignment Conditions and the Copy Theory: A Spanish Conspiracy. Em Nina Kazanina, Utako Minai, Philip J. Monahan \& Heather L. Taylor (eds.), University of Maryland Working Papers in Linguistics 14. 188-212. College Park, MD: UMWPiL.

Peres, João Andrade. 2013. Semântica do sintagma nominal. Em Eduardo Buzaglo Paiva Raposo, Maria Fernanda Bacelar do Nascimento, Maria Antónia Coelho da Mota, Luísa Segura \& Amália Mendes (coord.), Gramática do Português, vol. I. 735-815. Lisboa: Fundaçáo Calouste Gulbenkian.

Perlmutter, David. 1971. Deep and Surface Structure Constraints in Syntax. New York: Holt, Rinehart and Winston. http://hdl.handle.net/1721.1/13003

Philippaki-Warburton, Irena, Spyridoula Varlokosta, Michalis Georgiafentis \& George Kotzoglou. 2004. Moving from theta-positions: pronominal clitic doubling in Greek. Lingua: International Review of General Linguistics 114 (8), 963-989. https://doi.org/10.1016/S0024-3841(03)00100-1.

Pylkkänen, Liina. 2002. Introducing arguments. Massachusetts Institute of Technology. (Tese de doutoramento inedita).

Raposo, Eduardo Paiva. 1998. Some observations on the pronominal system of Portuguese. Catalan Working Papers in Linguistics 6, 59-93. https://ddd.uab.cat/record/2201.

Raposo, Eduardo Paiva. 2013a. Estrutura da frase. Em Eduardo Buzaglo Paiva Raposo, Maria Fernanda Bacelar do Nascimento, Maria Antónia Coelho da Mota, Luísa Segura \& Amália Mendes (coord.), Gramática do Português, vol. I. 303-398. Lisboa: Fundação Calouste Gulbenkian.

Raposo, Eduardo Paiva. 2013b. Nomes comuns. Em Eduardo Buzaglo Paiva Raposo, Maria Fernanda Bacelar do Nascimento, Maria Antónia Coelho da Mota, Luísa Segura \& Amália Mendes (coord.), Gramática do Português, vol. I. 947-989. Lisboa: Fundação Calouste Gulbenkian.

Raposo, Eduardo Paiva. 2013c. Pronomes. Em Eduardo Buzaglo Paiva Raposo, Maria Fernanda Bacelar do Nascimento, Maria Antónia Coelho da Mota, Luísa Segura \& Amália Mendes (coord.), Gramática do Português, vol. I. 883-918. Lisboa: Fundação Calouste Gulbenkian.

Rivas, Alberto. 1977. A Theory of clitics. Massachusetts Institute of Technology. (Tese de doutoramento inedita). http://hdl.handle.net/1721.1/16403

Roberts, Ian \& Anders Holmberg. 2010. Introduction: parameters in minimalist theory. Em Theresa Biberauer, Anders Holmberg, Ian Roberts \& Michelle Sheehan (eds.), Parametric variation: null subjects in minimalist theory. 263-302. Cambridge: Cambridge University Press. https://doi. org/10.1017/CBO9780511770784.001 
Roberts, Ian. 2010. Agreement and Head Movement. Cambridge, MA: MIT Press.

Roberts, Ian. 2012. Macroparameters and Minimalism: A Programme for Comparative Research. Em Charlotte Galves, Sonia Cyrino, Ruth Lopes, Filomena Sandalo \& Juanito Avelar (eds.), Parameter theory and linguistic change. Oxford: Oxford University Press, http://dx.doi.org/10.1093/ acprof:oso/9780199659203.003.0017

Runic, Jelena. 2014. A New Look at Clitics, Clitic Doubling, and Argument Ellipsis: Evidence from Slavic. University of Connecticut. (Tese de doutoramento inedita). https://opencommons.uconn. edu/dissertations/457

Schmitt, Cristina. 1996. Aspect and the Syntax of Noun Phrases. University of Maryland. (Tese de doutoramento inedita). http://ling.umd.edu/publications/103/

Sportiche, Dominique. 1996. Clitic constructions. Em Johan Rooryck \& Laurie Zaring (eds.), Phrase structure and the lexicon. Dordrecht: Kluwer Academic Publishers. 213-276. https://doi. org/10.1007/978-94-015-8617-7_9

Steriade, Donca. 1980. Clitic Doubling in the Romanian Wh-Constructions and the Analysis of Topicalization. University of Chicago. (Ms).

Stjepanovic, Sandra. 2007. Free word order and copy theory of movement. Em Norbert Corver \& Jairo Nunes (eds.), The Copy Theory of Movement. 219-248. Amsterdam: John Benjamins. https:// doi.org/10.1075/la.107.10stj

Strozer, Judith Reina. 1976. Clitics in Spanish. University of California, Los Angeles. Tese de doutoramento inédita.

Suñer, Margarita. 1988. The Role of agreement in clitic-doubled constructions. Natural Language and Linguistic Theory 6(3), 391-434. https://doi.org/10.1007/BF00133904.

Toledo Neto, Sílvio (em preparação). Demanda do Santo Graal: Edição do ms. 2594 da Biblioteca Nacional de Viena. (Ms).

Torrego, Esther. 1995. On the nature of clitic doubling. Em Hector Campos \& Paula Kempchinsky (eds.), Evolution and Revolution in Linguistic Theory. 399-418. Washington D.C.: Georgetown University Press.

Torrego, Esther. 1998. The Dependencies of Objects. Cambridge, MA: MIT Press.

Uriagereka, Juan. 1988. On government. University of Connecticut. (Tese de doutoramento inedita).

Uriagereka, Juan. 1995. Aspects of the Syntax of Clitic Placement in Western Romance. Linguistic Inquiry 26(1), 79-124. http://www.jstor.org/stable/4178889.

Van Urk, Coppe. 2015. A uniform syntax for phrasal movement: A case study of Dinka Bor. Massachusetts Institute of Technology. (Tese de doutoramento inedita). http://hdl.handle.net/1721.1/101595

Vergnaud, Jean Roger. 1974. French Relative Clauses. Massachusetts Institute of Technology. Tese de doutoramento inédita. 


\section{Apêndice}

A par do redobro de pronomes fortes, o redobro de DPs plenos, inexistente em PE standard, está atestado em fontes históricas desde o século XIII ao século XIX:

(i) e logo que for feyta disse(r) ca lha furtaró aq(ue)lla cousa q(ue) tija en encomẽda [Afonso X, Foro Real, séc. XIII; Ferreira (1987: 239), apud DVPM]

(ii) E porem dizemos que sse algûû fezesse dano de câpo. ou de vinha ou doutra cousa. ou ouuesse outro dereito ë ela $\&$ uisse ou soubesse que outro a demãdaua. ë juizo por aquel que fazia a demãda. bë pode o dono da cousa de poys. demãdar tha a quë quer que achasse [Afonso X, Partida III, séc. XIv; Caskey (1979), apud $\mathrm{CP}]$

(iii) Outro dia depois que o dia foi claro, sobiró ẽ seus caualos e tornaró ao castello por veer como thes aueera aos de dentro. [Demanda do Santo Graal, séc. Xv; Toledo Neto (em preparação), apud WOChWEL, DSG445,4]

(iv) Aquela barca aportou na pena e pareceo-lhe a el-rei que todos os bons cheiros do mundo i chegaram. [José de Arimateia, séc. xvi; Castro (1984), apud WOChWEL, JAR62,11]

(v) se o vigario estiver inebido pella inibitoria antáo the podeis dar ao conego esses papeis [Carta particular contendo instruçôes, séc. Xvir; P.S. Post Scriptum, PSCR9391]

(vi) mas agora Como veio a vizita e ouvi ler a pastoral dei Comta disto o Comfesor $\mathrm{p}(\mathrm{ar}) \mathrm{a}$ ver se estava este negosio bem detreminado $\mathrm{p}(\mathrm{ar}) \mathrm{a}$ eu ficase mais descansada e o Comfesor me detriminou que tho fizese a saber a V(osa) patrinidade o que agora faso [Carta particular de denúncia, séc. XviıI; P.S. Post Scriptum, CARDS1075,8]

(vii) e tinha dezejos de foder com ele e darlhe $\mathrm{m}$ (ui)tas pinguinhas a minha Rica pisinha tam bonita [Carta de amor, séc. XviII; P.S. Post Scriptum, CARDS3133]

(viii) entrando nesta vila de Salvatera $o$ quizerão prender ao Almocreve e elle fogio [Carta particular de pedido, séc. XIX; P.S. Post Scriptum, CARDS0002,5]

(ix) depois diçelhe o sorgião áo Patrão o Rapas more [Carta particular de denúncia, séc. XIx; P.S. Post Scriptum, CARDS0098,8]

Atualmente, o redobro de DPs plenos ocorre, pelo menos, em dialetos setentrionais e insulares. A construção está atestada no Corpus Dialetal para o Estudo da Sintaxe (CORDIAL-SIN):

(x) apanhou-lhe ao pai um cheque de cento e sessenta contos, [CORDIAL-SIN, VPA20,28]

(xi) Detesto aquela pessoa que the fuja com o valor a quem o tem. [CORDIAL-SIN, CTL44,5]

(xii) E não the podia dar nada ao senhorio. [CORDIAL-SIN, MST40,22] 
(xiii) Eu sei-lhos fazer os cartapácios. [CORDIAL-SIN, OUT16,29]

(xiv) mas não era a dar-lhe um murro à pessoa. [CORDIAL-SIN, FIG27,116]

(xv) Bota-lhe agora o milho ao gado que é horas. [CORDIAL-SIN, STA01,4]

(xvi) É a coisa que lhes faz melhor aos porcos! [CORDIAL-SIN, COV07,82]

(xvii) E eu vou-lhe dizer uma coisa à senhora: [CORDIAL-SIN, GRC30,79]

(xviii) Olhe, a senhora mostre-lhe ao meu marido. [CORDIAL-SIN, FLF05,3]

A utilização de pronomes fortes em vez dos correspondentes pronomes clíticos era recorrente até ao Português Médio, como refere Martins (1994: 202-213, 2016: $17-18)$ :

(xix) E deue colher a agua ẽessa parede en tal guisa que nô faça a nos dano ẽessas casas. [Documento do Mosteiro de Chelas, séc. XIII; Martins (2001: 352), apud WOChWEL, CHE1280,6]

(xx) E logo acudirom a elle todos os seus. [Crónica Geral de Espanha, séc. xIv; Cintra (1951), apud WOChWEL, CGE341,99]

(xxi) Uerdade he que eu amay், nó a muyto, hũa dona desta terra rica e poderosa e ella amaua a mỹ outro tanto ou maýs. [Demanda do Santo Graal, séc. Xv; Toledo Neto (em preparação), apud WOChWEL, DSG321,2]

(xxii) Sabede bem que, assi como ũu nom pôde ajudar, o outro menos pode ajudar $a$ vós. [José de Arimateia, séc. XVI; Castro (1984), apud WOChWEL, JAR105,110]

A utilização de pronomes fortes em contextos em que a variedade standard exigiria hoje o uso de pronomes clíticos está igualmente atestada no corpus CORDIAL-SIN. A dispersão geográfica deste tipo de dados, que se registam em todo o país, aponta mais para que a construção corresponda a uma marca generalizada de registo coloquial e não tanto a um traço específico de certas variedades regionais:

(xxiii) Chegue isto mais à frente que a mim dá mais jeito. [CORDIAL-SIN, CTL29,14]

(xxiv) Agora, disto das ovelhas, têm, às vezes, um rapazito para andar a ajudar a eles. [CORDIAL-SIN, ALC21,22]

Em certos dialetos do português (regiáo norte e Alto Alentejo), registam-se dados de redobro com o associado introduzido por para:

(xxv) E então, dizia-lhe o avô para o neto [CORDIAL-SIN, CTL18,92]

(xxvi) E digo-lhe eu assim para ele [CORDIAL-SIN, OUT15,64]

(xxvii) e diz-me assim para mim [CORDIAL-SIN, CBV11,28]

(xxviii)A tua mãe queria dar-lhe as nossas terras para ela. [CORDIAL-SIN, COV02,138] 


\section{Fontes dos dados do Apêndice}

CORDIAL-SIN = Martins, Ana Maria (coord.). 2000-. CORDIAL-SIN: Corpus Dialectal para o Estudo da Sintaxe / Syntax-oriented Corpus of Portuguese Dialects. http://www.clul.ul.pt/en/resources/ 411-cordial-corpus. (01/03/2018)

$\mathrm{CP}=$ Davies, Mark \& Michael Ferreira. 2006-. Corpus do Português: 45 million words, 1300s-1900s. http://www.corpusdoportugues.org/hist-gen/. (01/03/2018).

DVPM = Xavier, Maria Francisca, Graça Vicente \& Maria de Lourdes Crispim (orgs.). 1999-2003. Dicionário de Verbos do Português Medieval. http://cipm.fcsh.unl.pt/gencontent.jsp?id=5. (01/03/2018).

P.S. Post Scriptum = CLUL (ed.). 2014. P.S. Post Scriptum. Arquivo Digital de Escrita Quotidiana em Portugal e Espanha na Época Moderna. http://ps.clul.ul.pt. (01/03/2018).

WOChWEL = Martins, Ana Maria (coord.). 2012-2015. WOChWEL: Word Order and Word Order Change in Western European Languages. http://alfclul.clul.ul.pt/wochwel/index.html. (01/03/2018). 